\title{
Nuevos testimonios DE PEBETERos EN FORMA DE CABEZA FEMENINA EN LA CONTESTANia: LOS EJEMPlaRES DE AsPe E IFACH
}

\author{
New Evidences of Incense Burners in the Form of Female Head in the Contestania: the Aspe and Ifach \\ Exemplars
}

ENRIC VERDÚ PARRA

Museu Arqueològic d’Alacant - MARQ.everdu@diputacionalicante.es

RESUMEN:

A partir de la identificación de dos nuevos representantes de pebeteros en forma de cabeza femenina, ambos pertenecientes al modelo denominado "tipo Guardamar", y contando además con la ayuda de otros hallazgos recientes, el presente trabajo retoma el debate sobre la fabricación, origen, cronología y funcionalidad de estos peculiares objetos. Del mismo modo, el estudio busca trazar nuevas vías de análisis, incidiendo en el asunto de la producción indígena de estas figuras de terracota, con la intención de contextualizar estos materiales en el ámbito de la Contestania, región que se erige como un espacio de interacción a varios niveles entre comunidades ibéricas y poblaciones foráneas.

Palabras clave: pebetero, Aspe, Calp, cultura ibérica, Contestania.

\begin{abstract}
:
From the identification of two new examples of incense burners in the form of female head, both belonging to the model called "Guardamar type", and also counting with other recent findings, the present work resumes the debate about the manufacturing, origin, chronology and functionality of these peculiar objects. In the same way, the study seeks to trace new lines of analysis, focusing on the topic of the indigenous production of these terracotta figures, with the intention of contextualizing these materials in the ambit of the Contestania, a region that stands as an interaction space at various levels between Iberian communities and foreign populations.
\end{abstract}

Key words: incense burner, Aspe, Calp, Iberian culture, Contestania. 
El estudio de los denominados pebeteros de terracota en forma de cabeza femenina constituye un asunto muy recurrente en la bibliografía arqueológica desde que Ana María Muñoz publicara su trabajo pionero en 1963 y sobre todo con el descubrimiento de otros ejemplares, tanto de manera casual como durante el desarrollo de excavaciones arqueológicas. En este sentido, atendemos en este artículo a la reciente incorporación al corpus de pebeteros de dos nuevos representantes de la variante conocida como "tipo Guardamar", casualmente obtenidos mediante los procedimientos citados: el primero en las cercanías de Castillo del Río (Aspe) y el segundo en el transcurso de las actuales excavaciones en el Peñón de Ifach (Calp) (fig. 1). El detenido reconocimiento de ambos ejemplares, pese a su estado fragmentario y reducidas dimensiones, nos sirve como excusa para insistir de nuevo en el debate sobre la fabricación peninsular de estas figuras de terracota y su especial significado en los contextos indígenas.

\section{EL PEBETERO DE ASPE}

La primera de estas piezas de terracota (fig. 2) nos fue dada a conocer tras su donación, efectuada el 19 de septiembre de 2016, por el artesano ceramista Juan Antonio

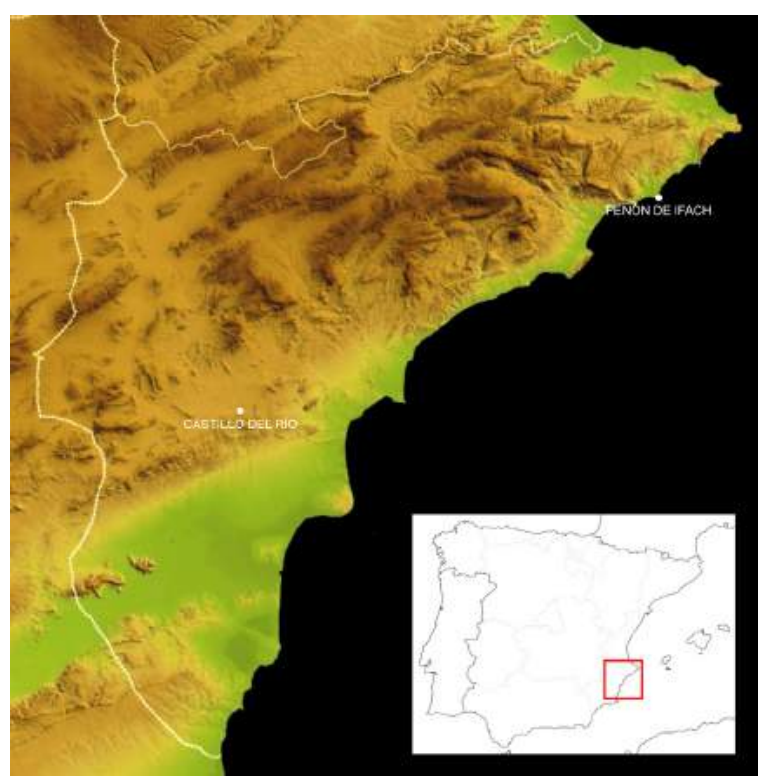

Fig. 1: Localización de los yacimientos en los que se recuperaron los fragmentos de pebeteros citados.
Pérez Meca al Museo Histórico de Aspe ${ }^{1}$, señalando como procedencia las cercanías del yacimiento arqueológico de Castillo del Río. Situado a unos $3 \mathrm{~km}$ al E de dicha localidad, su descubridor indica que la pieza se halló durante un paseo de reconocimiento de materiales geológicos, unos metros al NE del propio enclave arqueológico, volteada hacia abajo.

Con unas dimensiones de 5,6 cm de altura conservada y unos 4,4 cm de ancho, el fragmento corresponde a un rostro circular de rasgos desdibujados, observándose huellas de haber estado largo tiempo a la intemperie. Se intuye una pequeña nariz puntiaguda y un mentón redondeado, así como los pómulos, muy sutiles. No se aprecian los labios aunque sí los ojos, en especial el derecho, de forma almendrada, con el lagrimal suavizado y la comisura opuesta algo apuntada, delimitado por un reborde en bajorrelieve. Se reconoce el círculo del iris y una ligera cazoleta señala la pupila. La pasta es de color naranja, con desgrasante mineral casi inapreciable y algunas vacuolas en superficie. Al interior se distinguen con claridad algunas huellas digitales del alfarero.

El poblado ibérico de Castillo del Río (fig. 3) se sitúa sobre un cerro de $246 \mathrm{~m}$ de altitud al $\mathrm{S}$ de la confluencia de los ríos Tarafa y Vinalopó, en un punto estratégico que controlaría el paso desde el interior hacia la llanura de Elche y Alicante. Debió ocupar una extensión de unas 0,5 ha (Moratalla 2004: 254-256; 2015: 114-115), proporcionando las prospecciones realizadas en este paraje durante los años 70 materiales muy diversos, entre ellos cerámica ática de figuras rojas y barniz negro, campanienses, terra sigillata, común romana, africana de cocina, ibérica pintada con motivos geométricos e indicios de elementos vegetales y figurados, etc. ${ }^{2}$ (Llobregat 1972: 115; González 1975: 697-700). La ocupación antigua del lugar se dató ampliamente entre los ss. VI a.C. y V d.C. pese a que estos materiales siempre aparecieron en niveles de revuelto.

Las excavaciones emprendidas a partir de 1979 bajo la dirección de Rafael Azuar no constataron restos de construcciones antiguas (Azuar 1986: 112; 1994), sino de un poblado fortificado de época almohade (s. XII hasta la primera mitad del XIII) (fig. 4). En cuanto al yacimiento ibérico, únicamente se intuyen vagos indicios de una hipotética muralla derruida y una amplia dispersión de materiales, lo que, por otra parte, se ha tenido en cuenta para fijar un establecimiento de grandes proporciones, pese a encontrarse estos niveles arrasados 


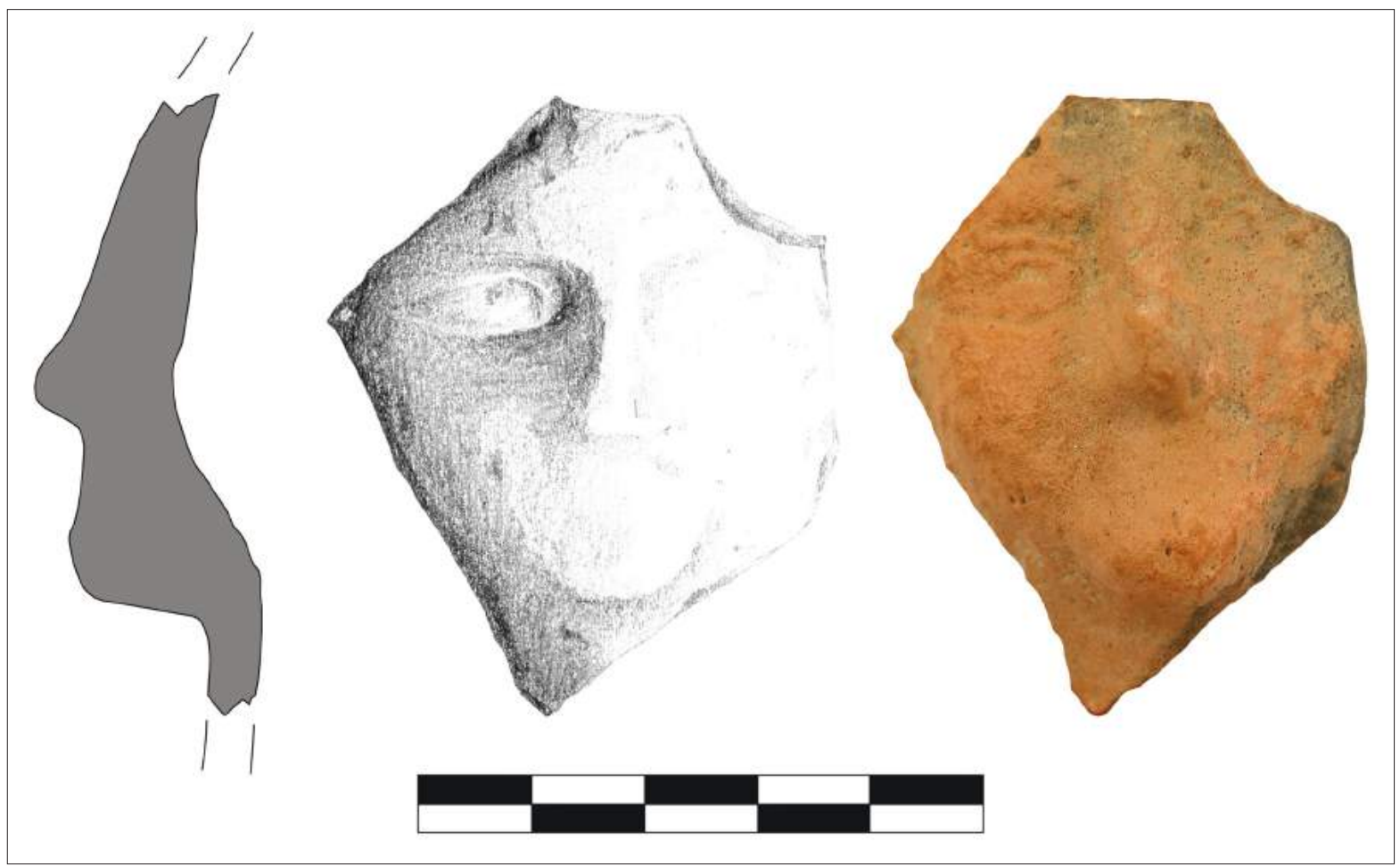

Fig. 2: Fragmento de pebetero de Aspe (dibujo del autor, fotografía Museo Histórico de Aspe).

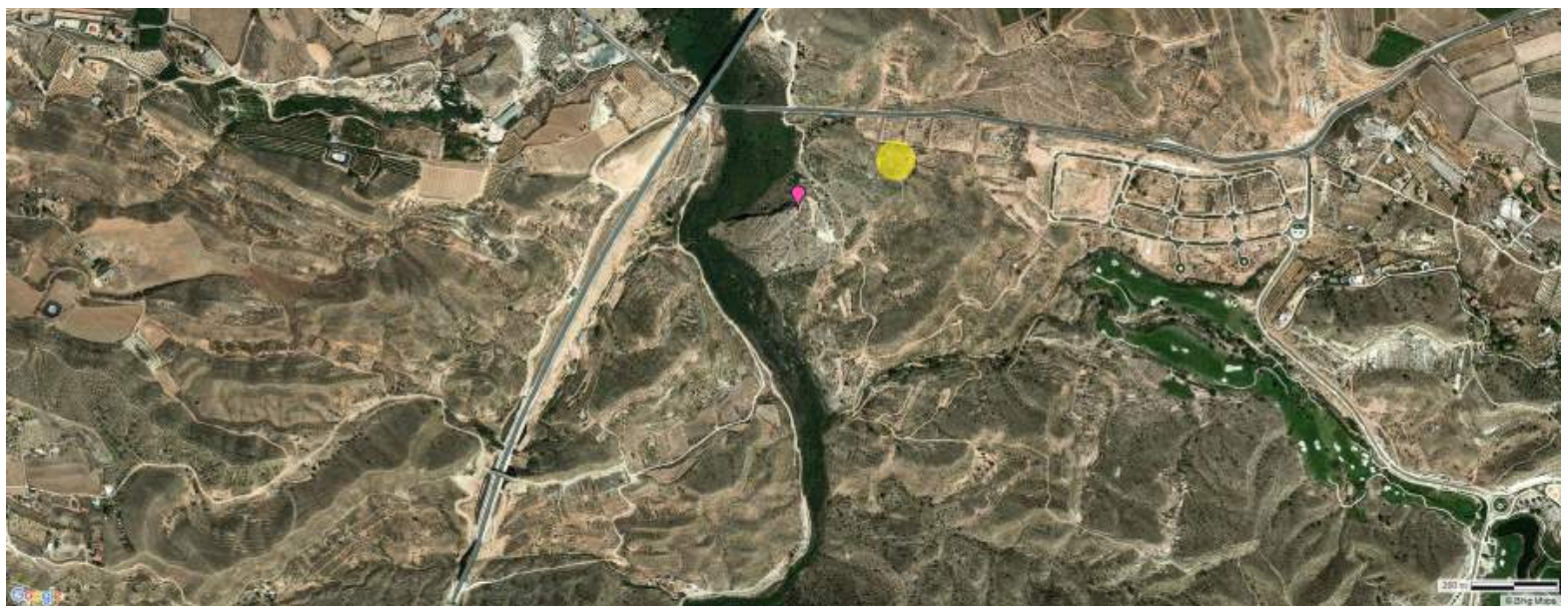

Fig. 3: Situación del yacimiento de Castillo del Río e indicación de la zona aproximada del hallazgo (fotografía Bing Maps).

por la fortificación islámica (García 2008: 91-93 y 151, fig. 45). A grandes rasgos, el registro parece informar de la existencia de un horizonte antiguo (ss. V-IV a.C.) y otro de época tardoibérica (II-I a.C.) (Moratalla 2015: 115), al que quizás correspondería el fragmento de pebetero descrito.

\section{EL PEBETERO DE IFACH}

En cuanto a las excavaciones desarrolladas durante los últimos años en la ladera del Peñón de Ifach (fig. 5), además de contribuir al conocimiento y puesta en valor de un importante hito arqueológico como es la pobla 


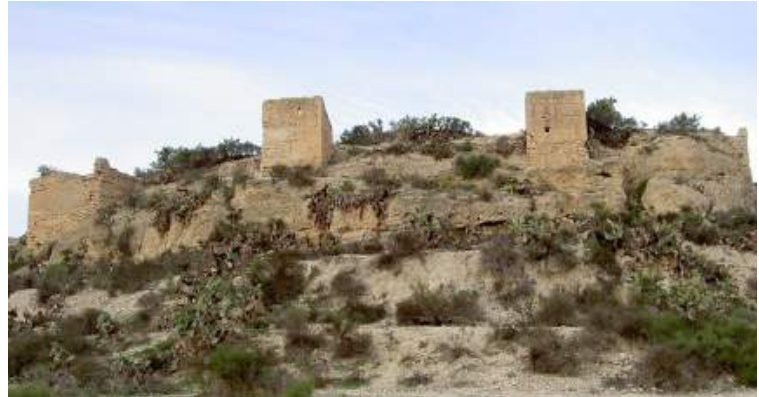

Fig. 4: Panorámica de los restos de la fortificación almohade de Castillo del Río (fotografía Juan Antonio Pérez Meca).

medieval allí asentada, han proporcionado un rico y variado elenco de objetos de mayor antigüedad, por desgracia carentes de contexto. Contando con los antecedentes de las primeras noticias e intervenciones en diversos puntos de este espectacular paraje ${ }^{3}$ (Verdú 2009: 69), los trabajos de inventario y catalogación permitirán caracterizar el hábitat protohistórico. El registro material sugiere, a priori, una prolongada ocupación ibérica, cubriendo prácticamente todas las fases de la evolución de esta cultura, pese a abarcar solamente entre 0,3 y 0,5 ha de extensión. Su existencia se fundamentaría en el control estratégico del territorio circundante (Grau 2004: 64 y 70-71).

En este sentido, y sin pretender profundizar en el asunto sobre todo por ser de trabajos en desarrollo y materiales en fase de estudio, destacaremos aquí por su singularidad e implicaciones el hallazgo de otro fragmento de terracota identificado como parte de un pebetero en forma de cabeza femenina (fig. 6). Se trata de un objeto dotado de un carácter muy especial, como quizás lo tuvo también el oinokhóe con representación de un jinete recuperado durante la campaña de 1975 (Verdú 2009), para el cual se ha determinado una cronología de entre fines del s. III a.C. e inicios de la siguiente centuria. En ambos casos puede hablarse de ítems vinculados a grupos aristocráticos, con una circulación restringida y un uso ritual. El descubrimiento del pebetero, por su parte, podría sugerir la existencia de un centro de culto o de un espacio sacro dentro de un ambiente doméstico. Lamentablemente las limitaciones del registro arqueológico impiden mayores precisiones.

El fragmento en cuestión ${ }^{4}$ fue hallado el 28 de julio de 2015 en el sector Muralla N (fig. 7). Conserva unos $5,8 \mathrm{~cm}$ de altura, $5,1 \mathrm{~cm}$ de ancho y un grosor máximo que alcanza los 1,65 cm. Corresponde básicamente a parte del rostro de un pebetero, elaborado en una arcilla medianamente depurada de tacto poroso y un tono anaranjado en superficie pero que en la fractura es gris intenso. El desgrasante, bastante visible, consiste en una mezcla heterogénea de pequeñas partículas blancas, negras, granates y diminutas trazas de mica plateada, mucho más escasas.

Para la fabricación de este objeto se empleó un molde algo desgastado o bien tal desgaste se debe a la erosión. Se aprecia la mejilla derecha y el arranque de un elemento ornamental, una especie de pendiente esférico o quizás una arracada compuesta por diversos granos, el modelo más habitual en este tipo de figuras (Horn 2011: 48-49). Se distingue también el ojo derecho, grande, rehundido y de forma almendrada, con el contorno en relieve. La nariz es de aspecto piramidal y con la punta redondeada, bajo la cual apenas se vislumbra la comisura de la boca. La barbilla es redondeada y poco pronunciada. La rotura no permite observar el resto de la cara, advirtiéndose al interior una superficie irregular y de nuevo algunas huellas digitales que el alfarero dejó sobre el barro tierno.

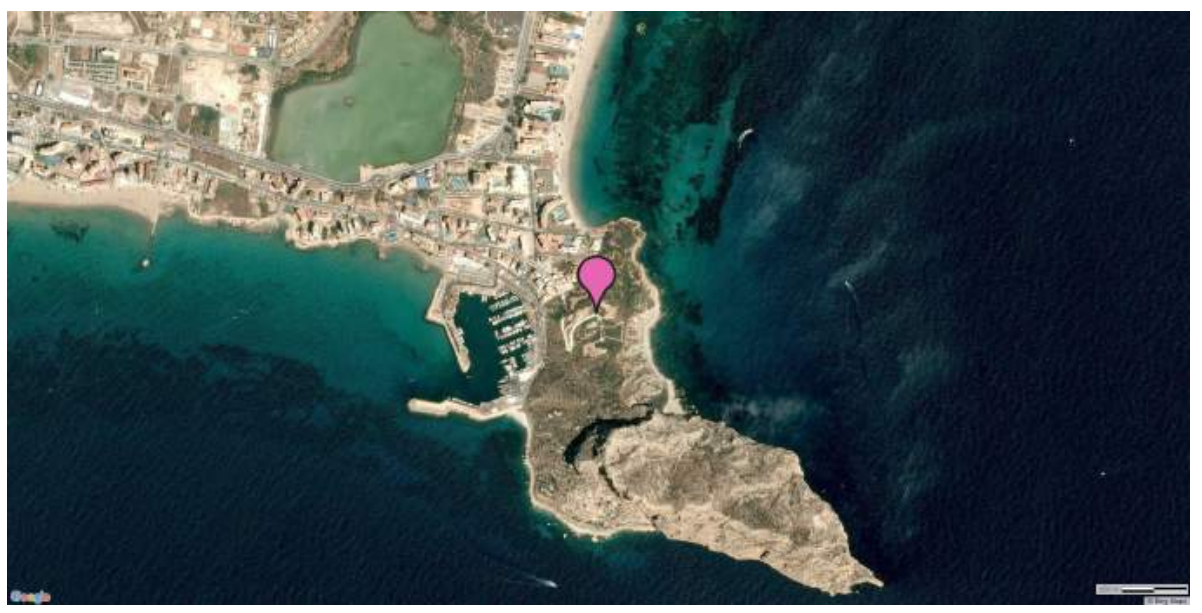

Fig. 5: Vista por satélite de Peñón de Ifach con indicación de las actuales excavaciones (fotografía Bing Maps). 


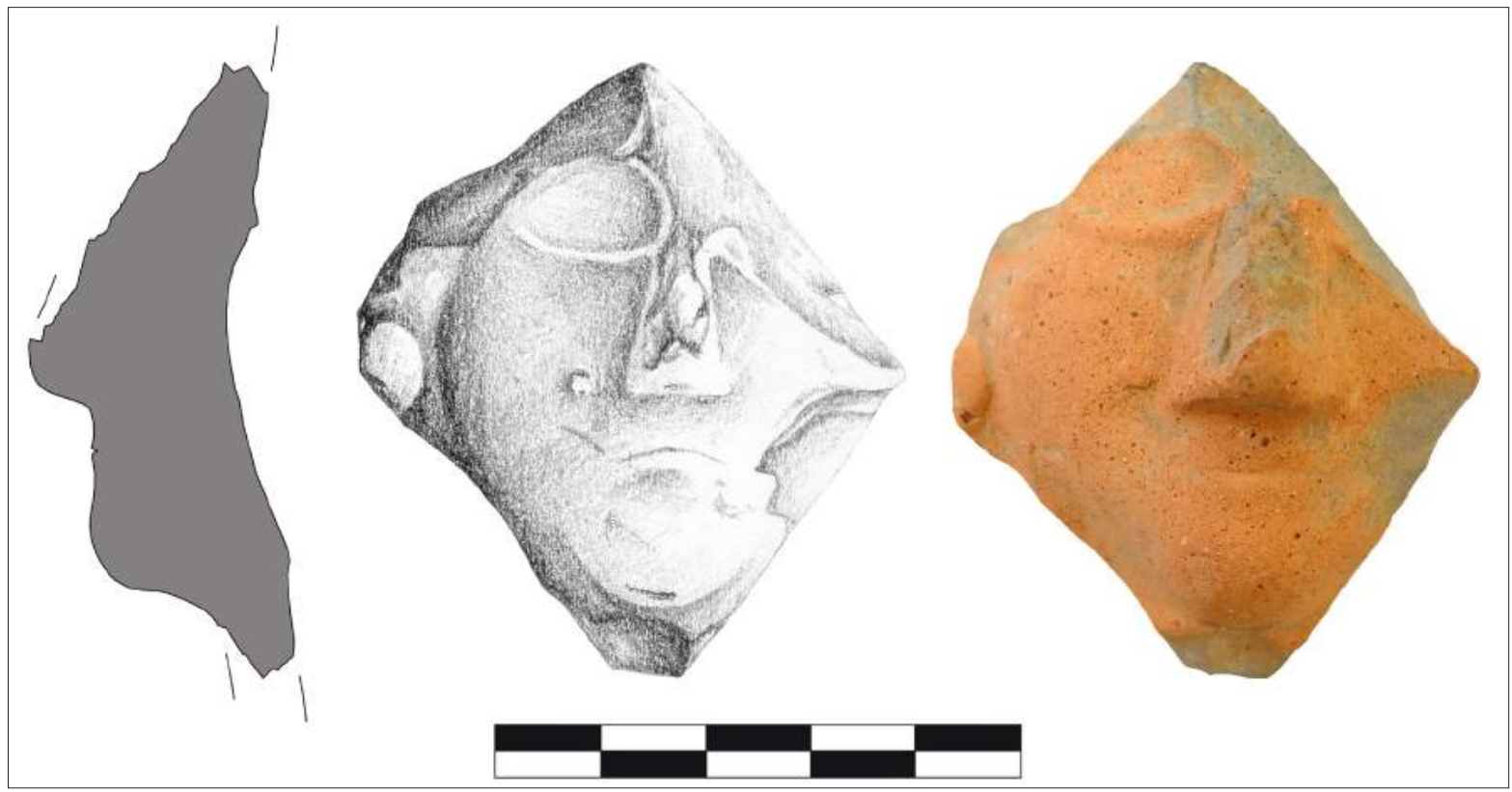

Fig. 6: Fragmento de pebetero recuperado en el Peñón de Ifach (dibujo del autor, fotografía Archivo Gráfico MARQ).

\section{SOBRE LOS PEBETEROS “TIPO GUARDAMAR"}

El reconocimiento de las características morfológicas (rasgos desdibujados, cara redondeada, ojos destacados y nariz pequeña, escaso relieve, etc.), su reducido tamaño ${ }^{5}$ y la composición de las arcillas (depuradas, con desgrasantes preferentemente calizos) de estos objetos no ofrece dudas sobre su correspondencia con el denominado "tipo Guardamar". Conviene recordar al respecto que este modelo no es recogido por Ana María Muñoz en su monografía por desconocerse aún los ejemplares de Guardamar del Segura. Esta investigadora sí menciona, en cambio, el hecho de que José Belda hallara en la ladera $\mathrm{N}$ del Tossal de la Cala (Benidorm) siete pebeteros similares a los de la necrópolis de l'Albufereta (Alicante) y un centenar de fragmentos de piezas del mismo tipo (Belda 1947; Muñoz 1963: 22), muchos de los cuales han sido recuperados gracias al programa de revisión de los materiales conservados en el MARQ (Bayo 2010: 122, fig. 69). Entre éstos se identifican varios fragmentos del "tipo Guardamar". Del mismo modo, y procedentes seguramente de excavaciones antiguas efectuadas en la Illeta dels Banyets (el Campello), se localizaron otros restos de pebeteros aún inéditos, entre los que también se reconoce al menos otro ejemplar similar, de gruesas paredes, pasta medianamente depurada color gris, bastante porosa, con vacuolas y desgrasantes de tamaño pequeño y medio ${ }^{6}$.

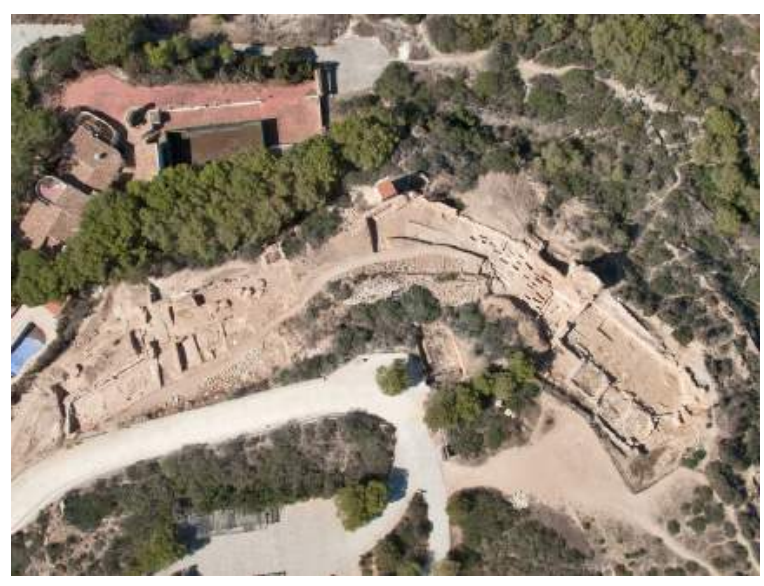

Fig. 7: Imagen aérea de las actuales excavaciones en la pobla de Ifac, en la que se aprecia el sector Muralla $\mathrm{N}$, la cual se desarrolla en sentido NO-SE (fotografía José Luis Menéndez Fueyo).

Los sondeos y prospecciones desarrollados en los años 80 en las laderas del Castillo de Guardamar proporcionaron un nutrido conjunto de pebeteros, así como otros materiales que abarcaban desde época ibérica hasta el s. XIX (Abad 1986; 1992: 225-228, cuadro 1; 2010: 123-125; García 1992-93: 68-69). Sin embargo, y pese a hallarse completamente descontextualizados, resultó más que llamativa la aparición de unos treinta individuos correspondientes a un tipo propio (Juan 1990: 141; Abad 
1992: 229 ss.; 2010: 126 ss.), para los que se ha atribuido una cronología genérica de los ss. III y II a.C. (Moratalla y Verdú 2007: 341 y 362), coincidiendo con la mayoría de pebeteros datados en contextos fiables ${ }^{7}$. Se describen como piezas con una forma muy definida, de tendencia cilíndrica, huecas y con una tapadera o "platillo" superior cóncavo, en ningún caso con perforaciones ni con huellas de fuego, en las que se representa un rostro aproximadamente circular, con rasgos apenas esbozados, nariz triangular prominente, mentón corto y boca apenas indicada (elementos constatados en los fragmentos de Aspe e Ifach), fuerte cuello delimitado en la parte inferior por el borde del escote y cabello dividido en dos sobre la frente, donde se intuye un disco central flanqueado por dos aves estilizadas y una pequeña moldura o baquetón precediendo un tocado cilíndrico o kálathos (fig. 8).

Más allá de esta descripción genérica, el registro de Guardamar permitió distinguir varios grupos a partir de los diferentes rasgos observables en estas terracotas. Atendiendo a los criterios fijados por Lorenzo Abad, el ejemplar de Aspe encajaría en el grupo 1, mientras que el fragmento de Calp podría clasificarse dentro del grupo 2, definido básicamente por la representación más realista del ojo, con los párpados indicados mediante un reborde que se curva hasta el lagrimal y una cazoleta interna en la pupila (Abad 1992: 231, fig. 5, nº 2, láms. IIC y III; 2010: 128 y 133, fig. 7). Este modelo, que Frédérique Horn establece como tipo P.5.2 (Horn 2011: 35 y 41-43, tabla 4, anexo I: 601-606), debió ser el más antiguo, derivando de éste los grupos 1 y 3 , con un aspecto más simplificado.

Entre los paralelos de estos pebeteros "tipo Guardamar", que debieron servir como una ofrenda muy común en determinados santuarios contestanos tardíos y cuya presencia se detecta desde la Serreta (Alcoi) hasta Villaricos (Almería) (Horn y Moratalla 2014: 159), cabe destacar precisamente los ejemplares localizados en el primer yacimiento, donde constituyen el modelo más habitual. En concreto, el 11\% de las terracotas atestiguadas aquí son pebeteros y entre ellos 34 individuos pertenecen al "tipo Guardamar" (Grau et al. 2017: 62-63 y 77 ss.). Jordi Juan los clasifica dentro del grupo VIII (Abad 1987: 164; Juan 1987-88: 314-315 y 323, láms. VI-VII; 1990: 141 ss.) (fig. 9, A) y establece a su vez una distinción partiendo de nuevo de la calidad y peculiaridades de la imagen femenina: los pebeteros del tipo I disponen de ojos grandes y pupilas indicadas, los del tipo II son de rasgos más simples y nariz ancha, mientras que los pebeteros del tipo III cuentan con los detalles muy esquemáticos, con los ojos y boca no señalados. Entre estas piezas se reconocen numerosas similitudes con los pebeteros de

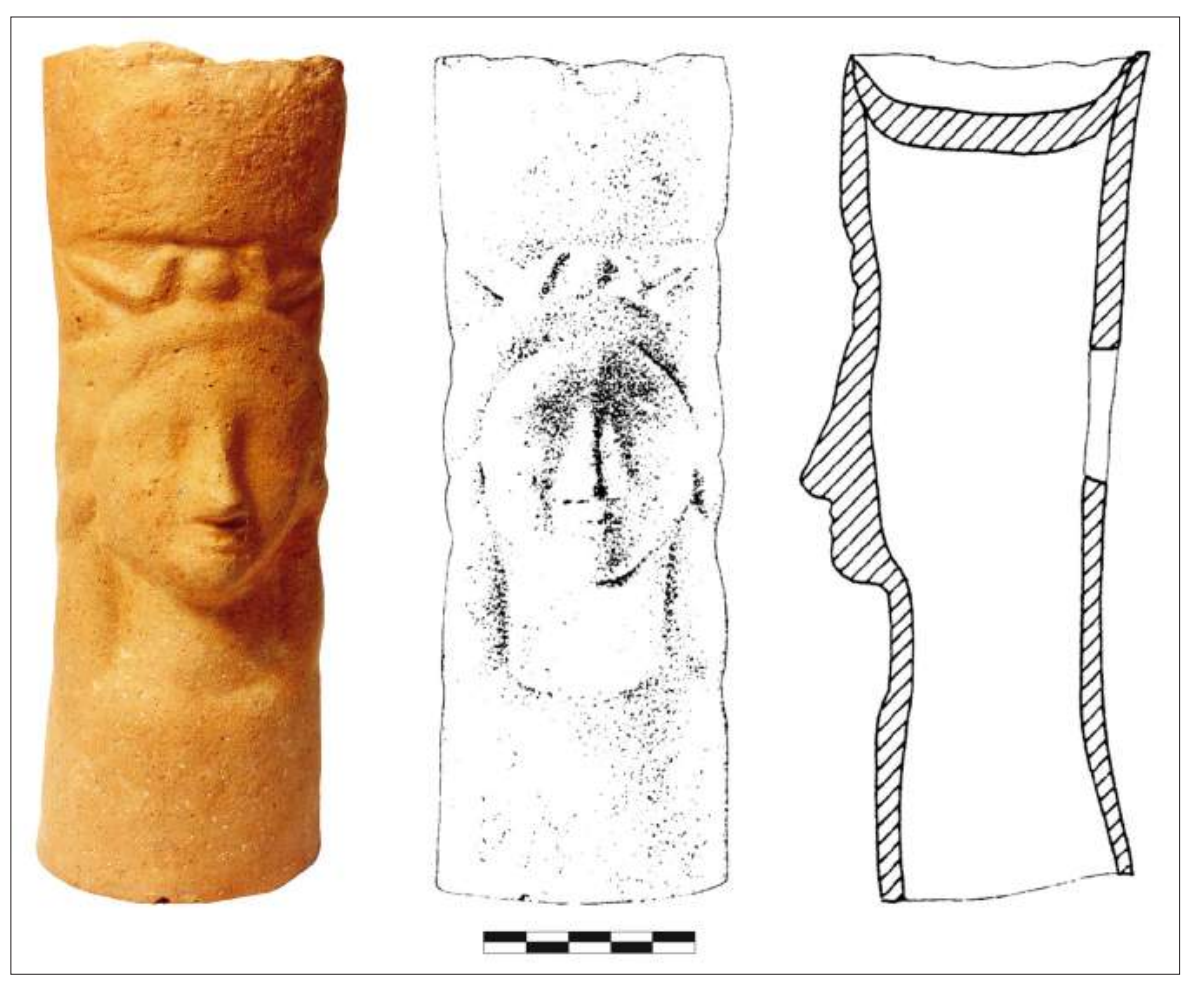

Fig. 8: Pebetero de Guardamar del Segura (Abad 2010: fig. 2; 1992: fig. 3). 
Fig. 9: A. Fragmentos de pebeteros "tipo Guardamar" del santuario de la Serreta (Grau et al. 2017: figs. 4.26-4.28). B. Ejemplar del tipo F de Villaricos (Horn 2014: fig. 5).

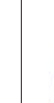

A
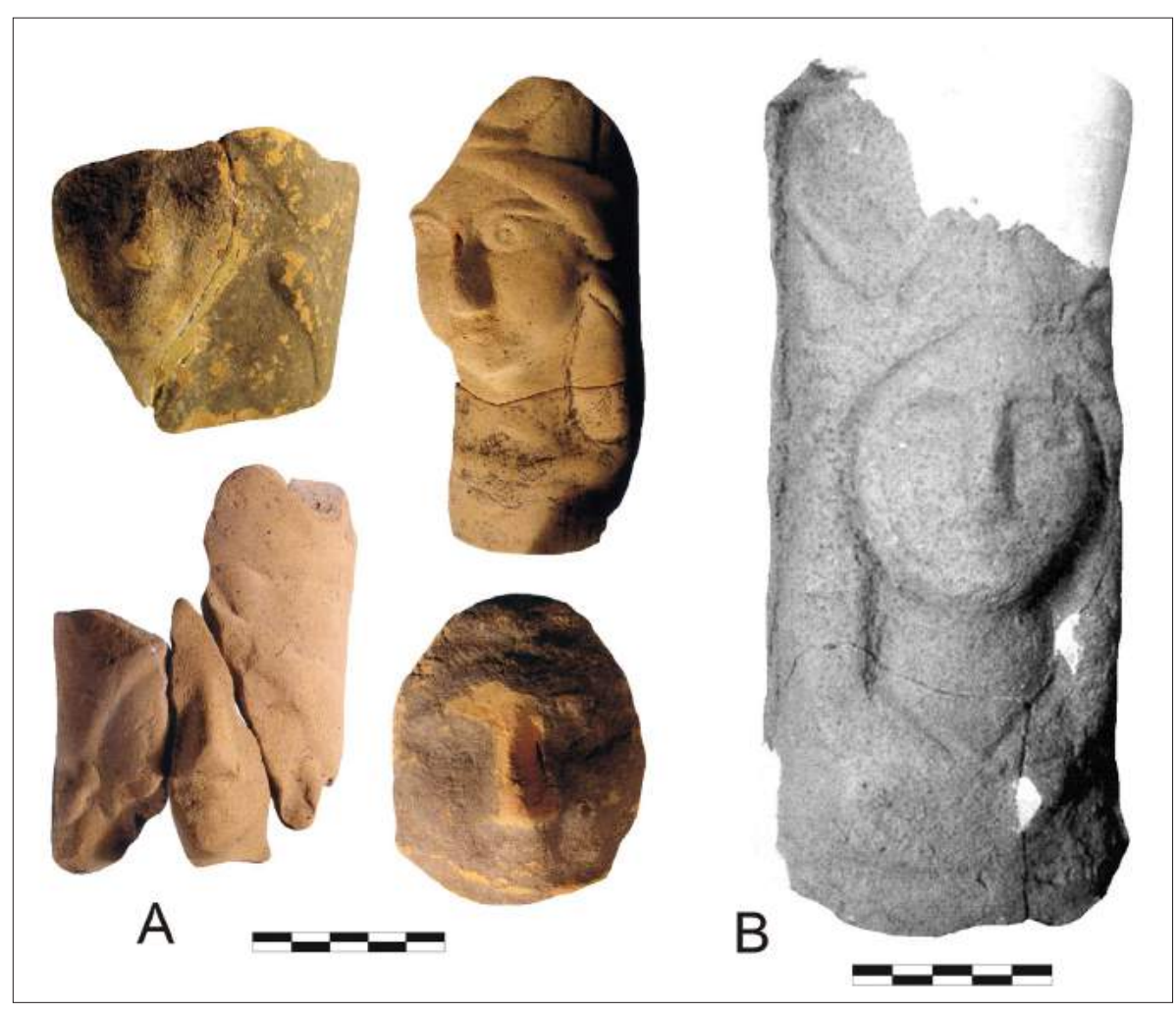

Guardamar, interpretándose como una manufactura indígena al servicio de un centro de culto ibérico situado en el interior de la Contestania.

En cuanto al yacimiento almeriense, el análisis de los ejemplares recuperados ha permitido desarrollar una clasificación en series diferenciadas e incluso la identificación de varias "generaciones" de pebeteros, confirmando la existencia de un taller vinculado a un santuario (Horn 2007: 257 ss.). Entre estas piezas se reconocen cinco individuos y diez fragmentos correspondientes al "tipo Guardamar" (Horn F) (fig. 9, B), para los que se determina una fabricación local posiblemente a partir de ejemplares contestanos importados (Horn 2007: 265 y 268, fig. 5; 2011: 139).

El "tipo Guardamar" constituye un modelo original de pebetero dentro de la Protohistoria peninsular en general y del mundo ibérico en particular, siendo característico de la regio contestana, donde es interpretado como una creación específica adaptada a las propias necesidades rituales a partir de una imagen muy común en el Mediterráneo central y occidental (Grau et al. 2017: 83). Por otro lado, la simplificación de los atributos en estas figuras, sobre todo en comparación con el tipo de pebetero "canónico", así como la tosquedad de ciertas representaciones, serían consecuencias más o menos voluntarias de una fabricación apresurada y a bajo coste, enfocada decisivamente a su amplia distribución entre las comunidades indígenas que las demandaban. Junto a los paralelos mencionados conviene incluir además los ejemplares de l'Alcúdia (Elx) (Moratalla y Verdú 2007: 344 y 346, lám. I; Horn 2011: anexo I: 596 y 605), en especial un fragmento localizado en el sector 10D (fig. 10, A) junto a material tardorrepublicano de los ss. II y I a.C.

Resulta de especial interés, como ya se ha señalado, el hallazgo de diversos fragmentos correspondientes al "tipo Guardamar" en la Illeta dels Banyets, actualmente en estudio. Es necesario aclarar que en el lote recientemente identificado en el MARQ se distinguen diferentes tipos de pebeteros, para los cuales no es posible concretar su procedencia exacta al pertenecer a excavaciones antiguas, si bien quizás se vinculen al "templo A" y, por lo tanto, a un ambiente cultual. Este mismo hecho se registra en el Tossal de la Cala y en el Tossal de la Malladeta (la Vila Joiosa), donde también se han descubierto fragmentos de pebeteros informando de un uso ininterrumpido del espacio como santuario costero al aire libre, entre mediados del s. II y fines del I a.C. Destacan aquí varios representantes del "tipo Guardamar", tanto del grupo Abad 1 como del 2, con pastas color beige muy depuradas, 


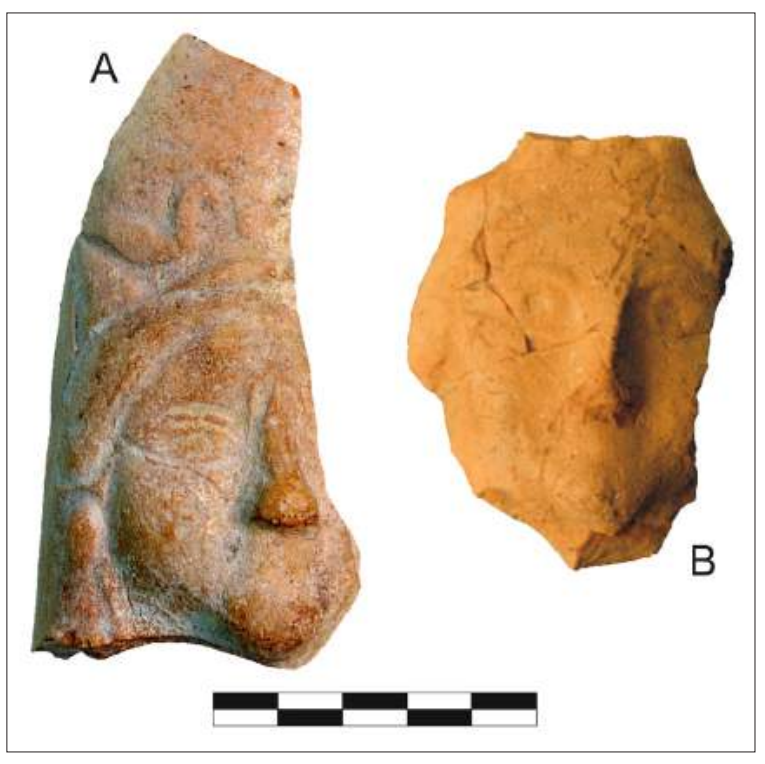

Fig. 10: A. Pebetero del sector 10D de l'Alcúdia (foto Fundación Universitaria La Alcudia, reproducida en Moratalla y Verdú 2007, lám. I). B. Fragmento recuperado en el Tossal de la Malladeta (fotografía VilaMuseu, Museu Municipal de la Vila Joiosa).

sugiriendo una producción local o regional (Horn y Moratalla 2014: 157-159 y 161-163) (fig. 10, B). Éste es el tipo más habitual en el santuario de Coimbra del Barranco Ancho (Jumilla) (García et al. 1991-92: 76 y 78, figs. I y II, $\mathrm{n}^{\circ} 1-2$, fotos 1-4; 1997: 241 ss.), un enclave que, pese a no encontrarse en la franja litoral, reúne buena parte de los condicionantes geográficos de los casos anteriores, y donde parece primar el interés estratégico por el control del territorio y las vías de comunicación.

\section{CARACTERÍSTICAS TÉCNICAS Y CENTROS PRODUCTORES}

Durante las últimas décadas se ha incrementado la cifra de pebeteros que fueron fabricados en la península Ibérica, confirmando las sospechas ya formuladas por la propia Muñoz (1963: 41), que ya intuía hace décadas que la mayoría de estas piezas no fueron importadas. Sin embargo, la falta de datos sobre los centros de producción siempre ha supuesto un obstáculo para la investigación, de ahí la importancia de hallazgos como el de la matriz del Tossal de les Basses (Alicante) (fig. 11), que pudo servir para la fabricación de pebeteros del "tipo Guardamar" (Rosser y Fuentes 2007: 98; Sala y Verdú 2014: 30, fig. 12).
La elaboración de estos objetos debió ser un proceso relativamente sencillo para los coroplastas peninsulares, cuya actividad cuenta con una notable tradición en el mundo ibérico, sobre todo a partir de su época plena. Por otra parte, recientemente se han publicado otros dos moldes identificados en Eivissa (Ramon 2011: 169, fig. 3, n ${ }^{\circ}$ 1; Costa et al. 2017), si bien ninguno de ellos se empleó para fabricar pebeteros. Sí que resulta interesante destacar que uno de ellos, de mejor factura y relacionado claramente con el vaciado de bustos femeninos de gran formato y estilo siciliota ${ }^{9}$, se recuperó en un sector entre la necrópolis de Puig des Molins y un barrio alfarero (Costa et al. 2017: 195), hecho coincidente con lo constatado en el Tossal de les Basses y que reforzaría la hipótesis de la producción local de estas terracotas.

En este yacimiento alicantino, y en un contexto de fines del s. III e inicios del II a.C., se localizaron también restos de tres vaciados pertenecientes al "tipo canónico" Muñoz A (Rosser y Fuentes 2007: 48-49 y 93; Sala y Verdú 2014: 28-29, fig. 10). Estos últimos, y siguiendo la opinión más extendida, serían los más antiguos, advirtiéndose pues dos momentos en su adopción y uso al parecer los de forma cilíndrica más tardíos. La cronología del poblado del Tossal de les Basses se establece entre fines del s. V y fines del III a.C., mientras que la del área productiva periurbana, en la que se descubrió el molde citado, se sitúa en época tardorrepublicana (Grau et al. 2017: 84). Pese a ello, no se puede descartar que la matriz la trajera consigo un artesano ceramista, independientemente de que éste ofreciera aquí o no sus servicios. En estos tiempos debieron existir artesanos itinerantes (alfareros, escultores, orfebres), dueños de sus propios medios de producción, que elaboraban sus obras por encargo. Más dudas presenta el caso de la Illeta dels Banyets, donde se localizó un alfar (López 1997; Olcina y López 1997) en el cual, no obstante, no hay testimonio alguno de que se realizaran pebeteros de cabeza femenina sino que se destinó básicamente a la fabricación de ánforas de tipología local.

Situaciones como la planteada por el Tossal de les Basses hacen hincapié en la cuestión de la hipotética convivencia de modelos en un mismo lugar y/o momento cronológico, lo que no siempre ha podido registrarse adecuadamente, como tampoco parece claro que los pebeteros "tipo Guardamar" pertenezcan necesariamente a los ss. II-I a.C. pues hasta la fecha siempre se han recuperado en posición secundaria o en contextos poco fiables (Sala y Verdú 2014: 30-33). Es más, durante el s. III a.C., en el 
que se han fechado durante los últimos años la mayor parte de los pebeteros conocidos (Verdú 2015: 250 ss.), pudieron utilizarse distintos tipos, no resultando tan relevantes para el comprador las características de su factura, morfología, tamaño y atributos representados como el contenido simbólico de que estas imágenes serían portadoras.

El vacío de información existente acerca de los centros productores, con excepción del caso ya referido de Villaricos o incluso del Tossal de les Basses, encuentra en Jumilla un nuevo hito. En las inmediaciones de Coimbra del Barranco Ancho pudo asentarse otro de estos talleres (García y Page 2004: 47-48), habiéndose identificado un lote de fragmentos de pebeteros correspondientes al tipo tubular, algunos en forma de discos recortados, con rasgos esquemáticos que encajarían en esta misma clasificación (un $17,48 \%$ del total), con tocado central, cabellos divididos sobre la frente, ojos almendrados con párpados y cejas levemente indicados, nariz chata y barbilla redondeada poco prominente (García et al. 1991-92: 76-82, figs. I-II, fotos 1-6; 1997: 241 ss., fig. 2, n 1-3; Moneo 2003: 138). En ningún caso cuentan con huellas de fuego, de ahí que haya que descartar su uso como quemaperfumes, y la cronología propuesta partiría de mediados del s. IV a.C., aunque la mayoría de los fragmentos aparecieron muy dispersos, integrándose quizás en una favissa o depósito ritual. Por otro lado, la variedad de pastas y calidad de la factura sugieren diversas procedencias.

Un caso muy similar, sobre el cual en los últimos años se han realizado interesantes avances, es el documentado en la bahía de Cádiz, donde el descubrimiento de multitud de pebeteros de factura local, sin tapadera perforada y raras señales de combustión, apunta a un uso preferente como exvotos (Niveau de Villedary 2007: 189-190; Verdú 2015: 261). De igual modo, la concentración de hallazgos en el territorio malacitano apunta también en la dirección de una fabricación peninsular para estas piezas, con una marcada tradición púnica, aunque elaboradas ya en el período romano republicano (Mora y Arancibia 2014). Esta idea viene reforzada por la singularidad de las producciones, caracterizadas por su esquematismo y, sobre todo, por la elección de pastas idénticas a las empleadas en la cerámica común desde época orientalizante.

En el mundo púnico no son raros los casos en que los centros alfareros se ubican en el entorno de los principales enclaves urbanos y necrópolis, como sucede en el S peninsular (Mora y Arancibia 2014: 52), configurando

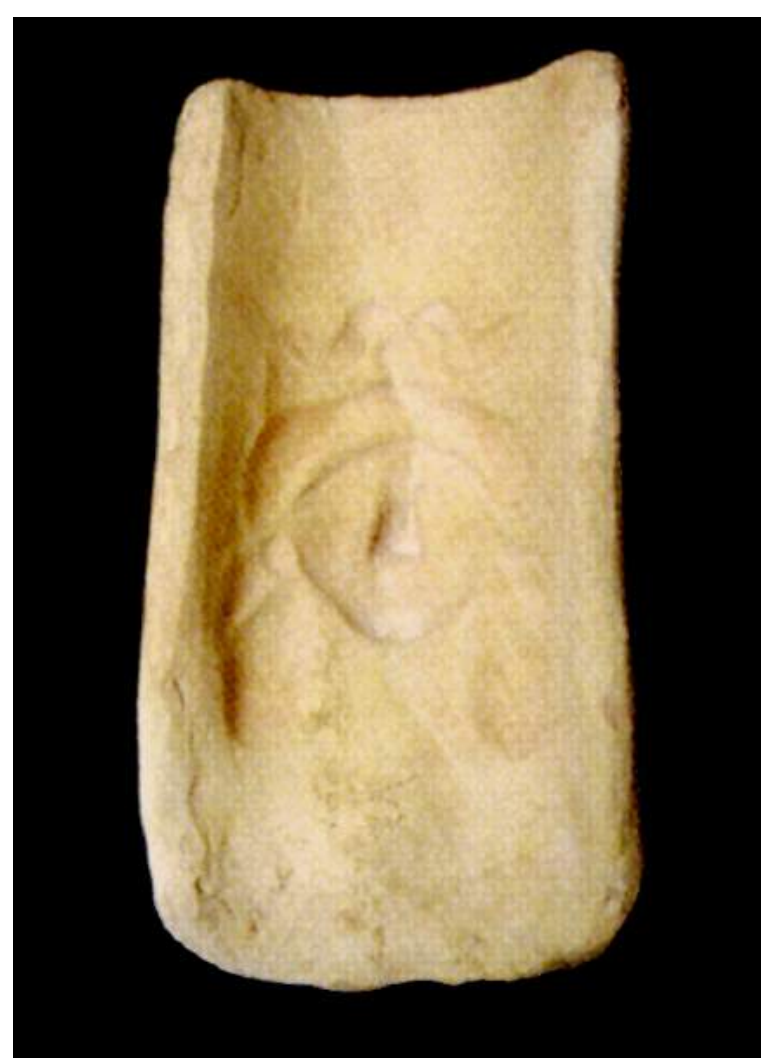

Fig. 11: Molde de pebetero "tipo Guardamar" localizado en el Tossal de les Basses (Rosser y Fuentes 2007: 98).

instalaciones suburbanas de diversa entidad dedicadas, entre otras actividades, a la producción de pebeteros y otras figuras de terracota de carácter votivo. Por su parte, el supuesto santuario del Castillo de Guardamar debió disponer de un carácter periurbano, al igual que el que pudo existir en la Serreta (Grau 2000: 212 y 216), siendo ambos conocidos sobre todo por las ofrendas recuperadas, entre las que destacan los pebeteros (Horn 2011: 203-205, tabla 33, gráfico 22; Sala y Verdú 2014: 24).

En cuanto a la factura técnica general de estos objetos, tradicionalmente se ha argüido una mayor calidad general de los ejemplares más antiguos y una progresiva degeneración del modelo, aunque en esta evolución, que habría que entender como no lineal, debieron intervenir otros factores como la pericia del artesano, la diversificación productiva de los diferentes talleres, la calidad de las matrices y el sobremoldeado, etc. (Niveau de Villedary 2007: 184). Conforme se sucederían las copias, iría reduciéndose el tamaño y el detalle de las mismas. Se registra así una amplia gama de tipos, variantes, pastas y acabados 
(García y Page 2004: 33), resultando habitual su coexistencia en un mismo establecimiento. Esta cierta "libertad formal" se debería sin duda a la ausencia de cánones rígidos en un sistema de producción de carácter artesanal, hecho que incluso se aprecia en los pebeteros norteafricanos (Niveau de Villedary 2017: 94-96).

Cada centro productor, e incluso cada artesano, pudo interpretar el prototipo original y reproducirlo de una manera particular, adaptando sus rasgos a las necesidades del culto o atendiendo simplemente a criterios prácticos (López et al. 2014: 80). Pese a todo, la decadencia artística es un hecho, de ahí que, a falta de localizar los alfares de origen, habitualmente se haya valorado el "tipo Guardamar" como una especie de imitación-degeneración del modelo "canónico" en un ambiente indígena (Abad 1992: 233; Moratalla y Verdú 2007: 358-359), en todo caso una invención plenamente contestana, empleándose en su elaboración matrices peninsulares (Pena 2007: 21), como parece confirmar el molde del Tossal de les Basses.

La mayoría de los ejemplares guardamarencos están elaborados con arcillas locales de tonos anaranjados a castaños, constatándose incluso pastas "tipo sándwich", siempre compactas y depuradas, con pequeños desgrasantes calizos o de colores granates o negros (Moratalla y Verdú
2007: 358-359). En el estudio practicado por F. Horn sobre los pebeteros del propio Castillo de Guardamar, el santuario de la Serreta, l'Alcúdia y Coimbra del Barranco Ancho, se aprecia un predominio de las arcillas de tonos ocre o beige bastante depuradas, con desgrasantes minerales de pequeño formato, sobre todo mica (García et al 1991-92: 76; Horn 2011: anexo I: 596 ss.). Para los pebeteros documentados en Cabecico del Tesoro (Verdolay, Murcia), donde se registra uno de los más importantes conjuntos de terracotas del SE peninsular, se indican pastas y acabados bastante uniformes, las primeras bien depuradas, de color beige al anaranjado o rojizo (García y Page 2004: 49). En la necrópolis de l'Albufereta, sin embargo, son muy variadas, al igual que las calidades y tamaños (Verdú 2005: 6163; 2015: 246 ss.), destacando incluso algunas piezas únicas. Cabe decir que en ninguna de estas dos necrópolis, en las que se recuperaron cerca de 80 ejemplares datados sobre todo en el s. III a.C., se identifican pebeteros de "tipo Guardamar", lo que sí sucede en la Serreta, donde disponen de pastas de tonos ocres claros, con desgrasantes medianos visibles, confirmando los recientes análisis arqueométricos (Gallello y Grau 2017; Grau y Gallello 2017; Grau et al. 2017: 83) que se trataría de una producción regional efectuada en algún punto del SE peninsular.

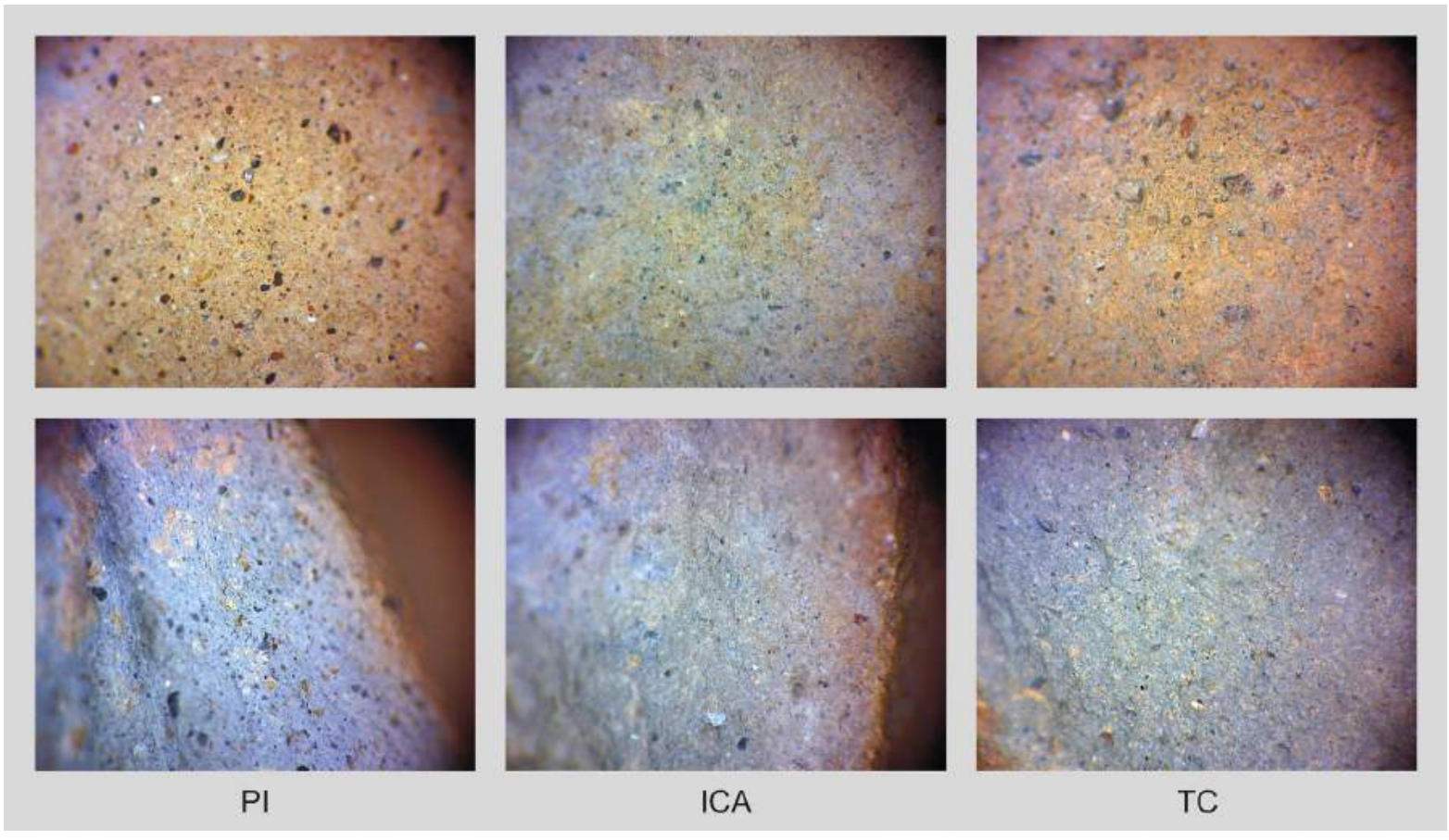

Fig. 12: Macrofotografías de la superficie y fractura de pebeteros de Ifach (PI), Illeta dels Banyets (ICA) y Tossal de la Cala (TC) (fotografías Archivo Gráfico MARQ). 
El reconocimiento visual de alguna de estas terracotas revela marcadas similitudes morfológicas, de coloración y composición de las arcillas (fig. 12), además de ciertos gestos de manufactura como son las huellas digitales derivadas al modelado, en ocasiones apenas suavizadas. Por ejemplo, es posible incluir en la misma categoría de pastas de un tono gris intenso al fragmento de Ifach, algunos ítems del Castillo de Guardamar, de la Illeta dels Banyets y el Tossal de la Cala ${ }^{10}$ (fig. 13). En este sentido, de manera preliminar, se ha desarrollado una primera clasificación de los pebeteros cilíndricos conservados en el MARQ a partir de diversos parámetros, paso previo para la selección de algunos representantes susceptibles de ser examinados con técnicas más efectivas, que podrán revelar si buena parte de estos pebeteros proceden de un mismo taller o, al menos, si la materia prima utilizada en su elaboración proviene de un mismo lugar ${ }^{11}$.

\section{EN TORNO AL ORIGEN, CRONOLOGÍA Y FUN- CIONALIDAD}

El estudio de los pebeteros en forma de cabeza femenina cuenta con una larga tradición historiográfica que ha atendido, entre otros aspectos, al tema de su denominación, funcionalidad y al origen del tipo iconográfico $(\mathrm{Mu}-$ ñoz 1963; Marín 1987; 2001-02: 319-323; Pena 1987; 2007; Ruiz de Arbulo 1994; García y Page 2004: 37 ss.; Horn 2011: 32 ss.). Estos elementos de coroplastia sirven de soporte a una iconografía de aire helenístico, aunque se trata de una creación púnica. El prototipo original procedería de la Sicilia púnica, desde donde estas piezas debieron difundirse hacia los principales establecimientos semitas del Mediterráneo centro-occidental (Cartago, Ebusus, Gadir) en los que, a su vez, se fabricaron nuevos modelos que evolucionaron de manera autónoma (Moratalla y Verdú 2007: 363 ss.; Verdú 2015: 252-253), se comercializaron y distribuyeron a nivel regional, ostentando Cartago el papel principal en la propagación no sólo de ejemplares físicos sino también de sus propias matrices (Niveau de Villedary 2017: 98-101).

Para el caso de la península Ibérica, la generalización de estos objetos se relaciona directamente con el período de las guerras entre púnicos y romanos y la movilidad de los ejércitos cartagineses. Sin embargo, como sugieren determinados ejemplares de l'Albufereta, el modelo parece introducirse ya en el s. IV a.C., aunque no se registran

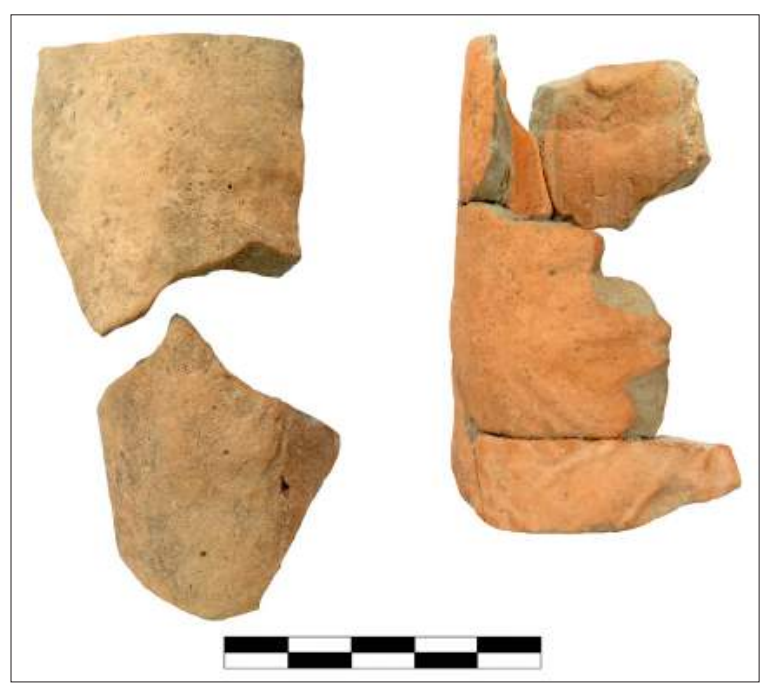

Fig. 13: Pebeteros "tipo Guardamar" con pasta gris de la Illeta dels Banyets (CS 14961) y Tossal de la Cala (CS 15291) (fotografías Archivo Gráfico MARQ).

pebeteros en todos los santuarios ni en todas las necrópolis, estando ausentes en algunas de época clásica como las de El Puntal (Salinas) o Cabezo Lucero (Guardamar), que no sobrepasan el s. IV a.C. El mayor número de ellos se concentra en la siguiente centuria (Moratalla y Verdú 2007: 362; Sala y Verdú 2014: 30-31; Verdú 2015: 254), alcanzando incluso el primer cuarto del II a.C. en la necrópolis murciana de Cabecico del Tesoro (García y Page 2004: 60-61) y cubriendo los dos últimos ss. antes del cambio de Era en algunos puntos más meridionales. Hasta fechas recientes se había insistido en la elevada concentración de estos objetos el en SE, la mayoría procedentes de santuarios (Horn 2011: 54-55 y 195 ss.), aunque el recuento de ítems se ha incrementado notablemente sobre todo a partir de los hallazgos efectuados en el área andaluza.

Entre la sociedad púnica debió asumirse esta iconografía magnogriega-siciliota, sin incorporar todo su contenido simbólico (Costa et al. 2017: 206-207). En cuanto a los ejemplares peninsulares, la opinión actualmente más generalizada incide en la rápida aceptación y adaptación de la imagen de los pebeteros, quizás Deméter, Astarté o Tanit, por parte de las poblaciones indígenas, si bien en el seno de estas comunidades, insertas en un espacio de interacción cultural con respecto a gentes foráneas, pudo ser interpretada como la representación de una divinidad propia cuyo nombre desconocemos (Moratalla y Verdú 2007: 361; Horn y Moratalla 2014: 162163; Niveau de Villedary 2017: 102), convirtiéndose en 


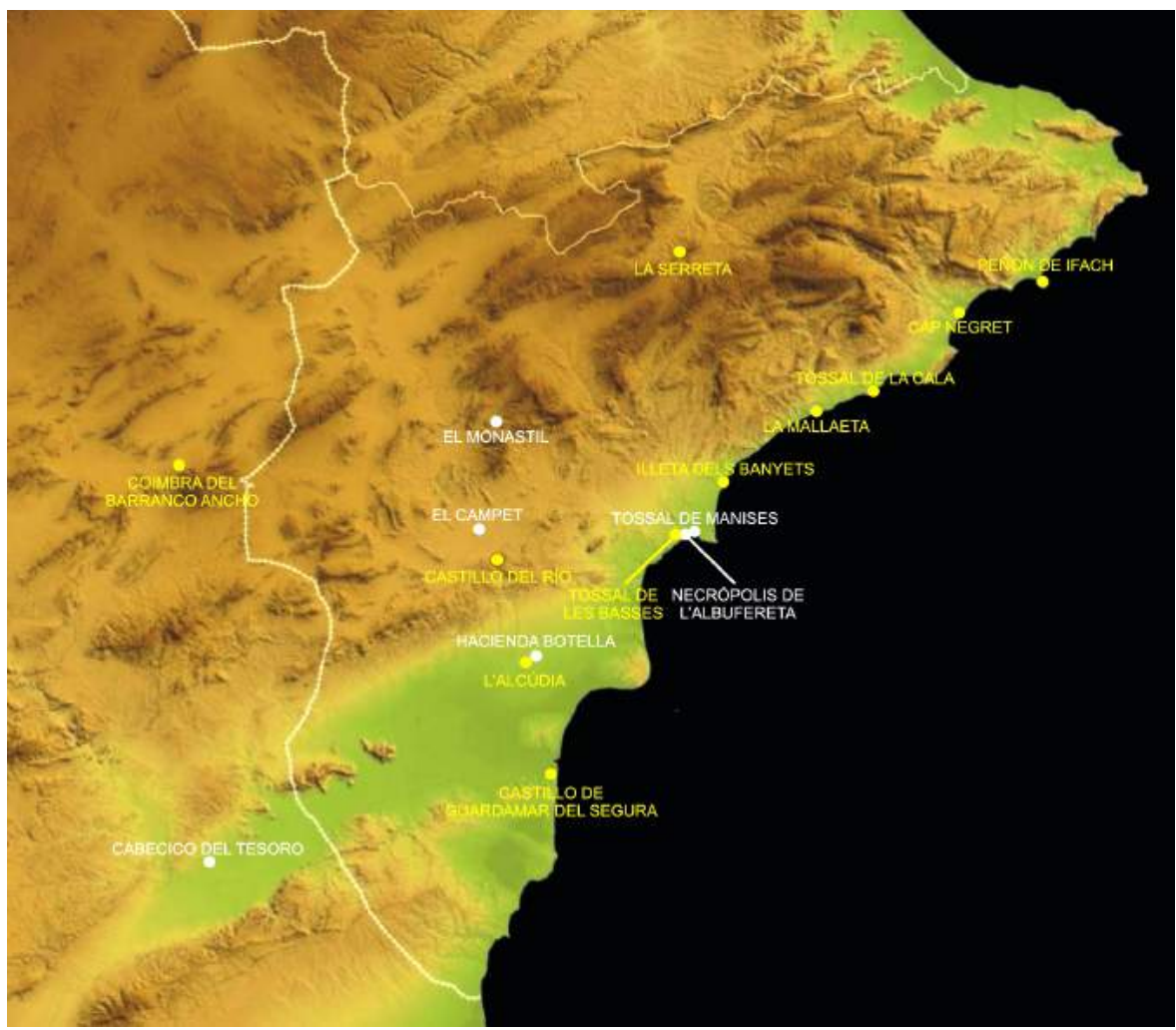

Fig. 14: Distribución de los pebeteros en forma de cabeza femenina en la Contestania ibérica, con indicación (en amarillo) de la presencia del "tipo Guardamar".

un nuevo y original elemento transmisor de los principales rasgos y atributos de la Diosa Madre ibérica. Es precisamente esta asimilación la que explicaría su difusión en la Contestania, máxime si en esta región existían contactos con el mundo semita desde hacía siglos (Abad et al. 2017: 233 ss.). En el SE peninsular debieron coexistir gentes de distintos orígenes (Aranegui y Vives-Ferrándiz 2014: 255; 2017: 32 ss.), generando un ambiente de intercambios comerciales y culturales en el que estas terracotas cobran sentido.

En cuanto a su funcionalidad, si bien no cabe duda de que los pebeteros primigenios pudieron servir como quemaperfumes o incensarios, los ejemplares ibéricos fueron básicamente exvotos, siguiendo una costumbre ancestral consistente en depositar objetos de naturaleza diversa (vasos cerámicos, figurillas de barro o metal, alimentos sólidos o líquidos), constatada sobre todo en santuarios, capillas domésticas y sepulturas (Moneo 2003: 360 ss.; Pena 2007: 28-29; García 2015: 94; Verdú 2015: 261263). La ausencia de huellas evidentes de fuego, como sucede también en los fragmentos de Aspe e Ifach, y, en concreto, la falta de los cierres superior y/o inferior en muchos pebeteros "tipo Guardamar", confirman este nuevo aprovechamiento, que sólo se alcanzaría tras una familiarización con el objeto originario (Grau et al. 2017: 83).

Tomando como referencia los primeros pebeteros llegados a estas tierras debieron generarse nuevos tipos en distintos focos, de ahí la imposibilidad de establecer una “cronología tipológica" (Pena 2007: 30), a lo que habría que añadir la pervivencia de muchas piezas en un mismo tiempo y lugar. No sólo se aprecia una miscelánea morfológica en el registro de la necrópolis de l'Albufereta (Verdú 2005: 61-63; 2015: 246 ss.), sino que esto ocurre igualmente en la Illeta dels Banyets o en el Tossal de la Cala (Bayo 2010: 116 ss.). El repertorio de Guardamar, sin embargo, es más uniforme, resultado más que probable de la producción de un taller especializado cercano.

Junto a la confirmación del mayor peso de los vaciados ibéricos con respecto a los pebeteros importados, se considera que la producción peninsular arrancaría en el s. III a.C., multiplicándose los talleres locales durante su segunda mitad (Ferrer y Prados 2007: 135 y 137; Horn 2011: 63). Este hecho se constata además en la Gadir púnica, donde los recientes hallazgos corroboran la existencia de una producción artesanal de manufacturas de carácter votivo y, concretamente, de estos pebeteros a partir moldes 
y terracotas llegados entre mediados del s. III a.C. y el estallido de la $2^{\text {a }}$ Guerra Púnica (Niveau de Villedary y Córdoba 2003: 127-130, figs. 4-5, láms. I-IV; Niveau de Villedary 2007: 151 ss.), prolongándose hasta la época republicana (Niveau de Villedary y Blanco 2007: 197 y 203-208, fig. 7, lám. II). Por otra parte, la derrota cartaginesa no supuso una brusca ruptura en las estructuras socioeconómicas de los territorios afectados, constatándose además una pervivencia de usos y costumbres al menos hasta avanzado el s. I a.C.

La ausencia del "tipo Guardamar" en la Serreta, donde sí se documentan figurillas esquemáticas o realistas realizadas a mano, incide en una cronología avanzada para estos pebeteros (Amorós y Grau 2017: 166; Grau et al. 2017: 83). Por otro lado, el registro arqueológico indica que el territorio del Bajo Segura se encuentra prácticamente deshabitado desde el final de la $2^{\text {a }}$ Guerra Púnica hasta época augustea (Moratalla 2005: 109; Olcina 2010: 137-140; Sala y Verdú 2014: 32; García 2015: 84 y 88), hecho que se contradice con la habitual cronología tardía asignada a los pebeteros de Guardamar. Tal contradicción no dispone hoy de solución posible debido a las limitaciones del registro arqueológico, no pudiéndose descartar en este caso ciertas frecuentaciones puntuales.

Centros de culto como los que debieron existir en la Serreta, el Castillo de Guardamar o Coimbra del Barranco Ancho, son propios de un período más bien avanzado dentro de la Cultura Ibérica, y en ellos debieron emplearse los pebeteros como medio de expresión de la religiosidad indígena. En el caso guardamarenco, la vocación marinera del lugar es más que evidente, de ahí que se haya considerado incluso como un "santuario portuario" (García 1992-93; Moneo 2003: 124 y 141), dada su situación preeminente en la desembocadura del Segura, vía de comunicación hacia el interior de Albacete, la Andalucía oriental y el Alto Guadalquivir. Algo similar ocurre en Baria, donde también se constata un santuario extraurbano muy cerca de la margen izquierda del río Almanzora, que en la Antigüedad conformaba un estuario (López 2001-02: 77-78, fig. 1), efectuándose en él un importante depósito de terracotas, entre ellas pebeteros (Almagro, 1983). También se registran en ambientes cultuales en las Islas Baleares, caso de Menorca, por lo general con una característica forma de carrete e indicación del velo, acompañando en ocasiones a otras figurillas (Niveau de Villedary 2017: 88-90, fig. 3). La isla de Ebusus pudo ejercer como principal fuente de inspiración en la fabricación de estas piezas
(López et al. 2014: 78-79), pese a la gran cantidad de talleres que operaron tanto en la isla como en Cerdeña y en el ámbito ibérico.

En lo referente al área contestana cabe destacar la distribución fundamentalmente costera de estos objetos de terracota (fig. 14), asociados con frecuencia a santuarios (Abad 1992: 233; 2010: 132). Algunos de ellos, además, dominan la desembocadura de los ríos, vinculándose así con el control del tráfico marítimo y fluvial, de ahí la elección preferente de cerros situados cerca de las vías de comunicación y de los núcleos urbanos pero a una cierta distancia de éstos (Sala y Verdú 2014: 34; García 2015), esquema claramente constatado en el ámbito fenicio-púnico meridional (Ferrer 2002: 195 ss.). El de Guardamar debió ser un lugar de culto al aire libre en un paraje elevado, siguiendo el modelo de otros santuarios que vigilan los estuarios de ríos navegables y las vías de penetración hacia el interior (Abad y Sala 1997: 101; García 2015: 83-84). Casualmente, a los pies de Castillo del Río discurre el Vinalopó, siendo éste un territorio que actúa de frontera entre la Contestania y el interior, que se beneficia de la riqueza de agua y de unas tierras aptas para el cultivo (García 2008: 145). El interés estratégico y la cercanía a áreas de recursos serían condicionantes clave para el poblamiento (Moratalla 2015: 117), de ahí la importancia del emblemático yacimiento de Tres Hermanas (Aspe) (García y Moratalla 1998-99; Rouillard et al. 2015), que controlaría entre los ss. V y IV a.C. el tránsito de productos agropecuarios y mercancías suntuosas llegados desde el Mediterráneo, es decir, las relaciones comerciales entre los centros receptores de la costa y los núcleos de poblamiento del interior.

Por otro lado, a partir del registro material, que no de los restos arqueológicos constructivos, se intuye una destacada importancia para el establecimiento ibérico de Ifach, debido sobre todo a su privilegiada situación, como sucede con Cap Negret (Altea), el Tossal de la Cala o el propio Tossal de Manises (Verdú 2009: 83), lugares todos ellos en los que se han recuperado, en mayor o menor medida, pebeteros en forma de cabeza femenina. En el caso calpino, se presupone una ocupación ya en el s. IV a.C., frente al mar y en conexión visual con un amplio espacio de albufera y con el hito geográfico de la sierra de Bernia, cerca de la cual se localizaron además los vestigios de una torre de vigilancia ibérica, el Tossal de l'Empedrola (Bolufer y Sala 2009) (fig. 15). Este hecho, junto al control costero y al nada desdeñable conjunto cerámico detectado, reforzaría su posición de dominio estratégico en la zona. 

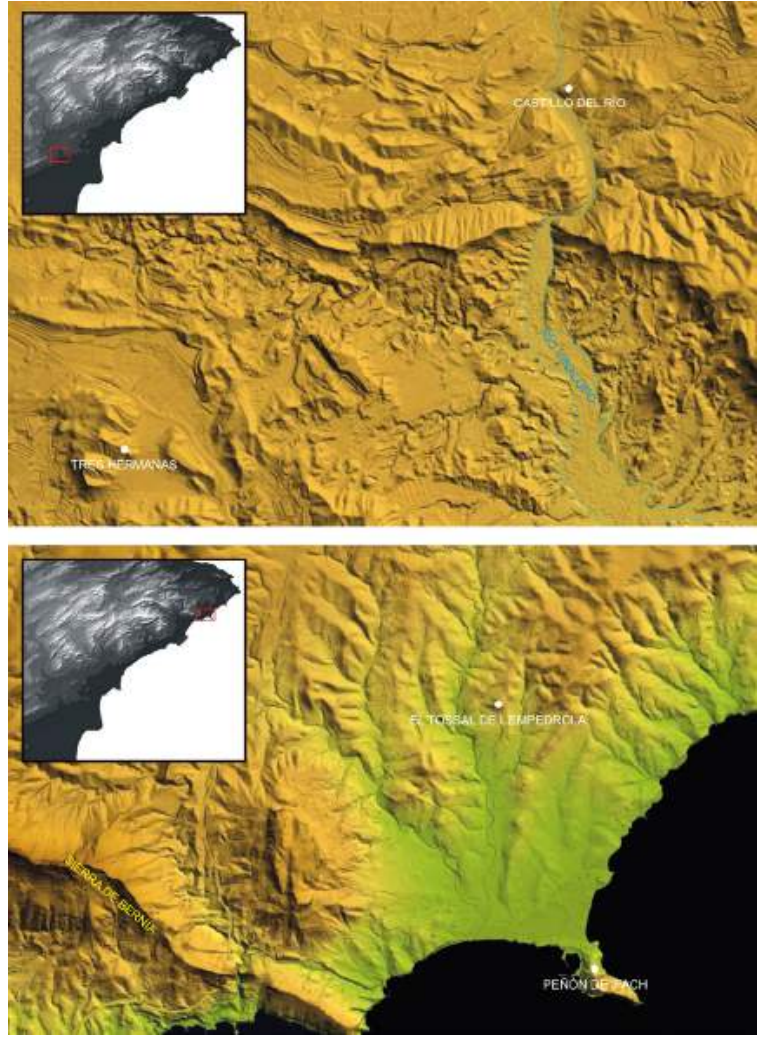

Fig. 15: Localización de los yacimientos de Tres Hermanas y el Tossal de l'Empedrola con respecto a Castillo del Río y Peñón de Ifach respectivamente.

Cabe decir en relación con todas estas cuestiones, que ya C. Aranegui (1994) señalaba la existencia de "lugares sacros litorales", definidos por un área sacrificial y almacenes para productos de consumo (Gusi 1997: 173). Más recientemente se ha insistido en un uso ritual de determinados espacios costeros o visibles desde el litoral (Aranegui 2015: 19-20; Aranegui y Vives-Ferrándiz 2017: 41-42), constituyendo un claro ejemplo de paisaje ritualizado las denominadas "cuevas santuario" (López-Bertran 2015), situadas en puntos estratégicos en los que, como sucede en la Contestania, se han recuperado objetos con un significado simbólico. Si entendemos los pebeteros como ofrendas a una divinidad preeminente, tal circunstancia explicaría en buena medida su presencia abrumadora en casos como el de Guardamar, aunque no tanto en otros como los de Aspe o Ifach, donde aparecen de manera más puntual (o aún no se han descubierto), contando, sin embargo, con un mismo sentido y funcionalidad. Su depósito sería un acto piadoso que cobraría especial significación por la excepcionalidad del lugar en que se efectúa la ofrenda.
Estos yacimientos del litoral alicantino serían centros receptores tanto de ideas como de costumbres y productos foráneos, no debiendo importar tanto el aspecto definitivo del exvoto, de ahí la convivencia de diferentes modelos de pebeteros, como su contenido simbólico. Destaca particularmente el enorme atractivo comercial de las zonas de desembocadura de ríos, fácilmente navegables y rodeadas de tierras fértiles, en una de las cuales se instalaría el santuario de Guardamar (García 1992-93: 86; Abad y Sala 1997: 100-101), que pudo ser un recinto al aire libre, como también se ha interpretado en ocasiones el denominado "templo B" de la Illeta dels Banyets. Junto a las plataformas centrales del interior de este último edificio apareció un pebetero muy similar al hallado en la conocida como "casa del cura" (Olcina et al. 2009: 158; Sala y Verdú 2014: 21 y 23, figs. 2, 5 y 6), por lo que se considera que el templo estuvo consagrado a una diosa relacionada con la fertilidad y con el mundo de ultratumba (Llobregat 1988: 142). Todo hace pensar en una práctica religiosa de raigambre púnica, comprensible por la población local, que serviría para reforzar sus lazos de unión en torno al culto a una divinidad común que auspiciaría los encuentros efectuados en este centro comercial. De este modo, la imagen de los pebeteros sugiere un sincretismo, un culto compartido por indígenas y extranjeros a una deidad agraria pero con una vinculación al mar (Perdiguero 2016: 56 y 63). Del mismo modo, convendría valorar la posibilidad de algún tipo de sanción sagrada de las transacciones comerciales desarrolladas en estos enclaves, como recientemente se ha estimado también para el caso de la Illeta (Perdiguero 2017).

A partir del s. IV a.C. las manifestaciones religiosas se diversifican significativamente en el seno de la Cultura Ibérica (Gusi 1997: 175-177), identificándose conductas rituales tanto en recintos construidos ex profeso como en espacios naturales como cuevas y abrigos. En todo ello influye tanto la propia evolución interna de la Cultura Ibérica como la circulación de mercaderes y productos, fundamentalmente desde la costa hacia el interior pero también conviene valorar las relaciones a nivel regional. Como resultado del surgimiento de nuevos (y no tan nuevos) espacios de interacción entre indígenas y foráneos, debió producirse un fluido intercambio de conocimientos y creencias que contribuyeron a superar el tradicional "aniconismo ibérico" con la aceptación y normalización del empleo de exvotos de aspecto figurativo. Tales objetos pudieron almacenarse temporalmente en depósitos o tesauros específicos ubicados en departamentos contiguos 
a los recintos sacros, como ocurriría en la Serreta o Guardamar. Cabe decir que el depósito de exvotos es el ritual básico practicado en los santuarios de Iberia, pese a contar en cada región con sus propias peculiaridades. Mientras que en el área de Jaén abundan las figurillas de bronce, en el Cerro de los Santos (Montealegre del Castillo, Albacete) se prefieren las representaciones pétreas de oferentes y en la Serreta se opta exclusivamente por piezas de terracota.

En lo relativo a los pebeteros en forma de cabeza femenina, durante largo tiempo ha existido un cierto consenso al considerar que agentes púnicos se encargaron de la transmisión de un modelo generado a partir de prototipos siciliotas, llegando los primeros ejemplares a la península Ibérica antes del episodio bárquida, si bien es a partir del s. III a.C. cuando son mucho más abundantes. Más allá de estos planteamientos de carácter difusionista, el uso de estas piezas como quemaperfumes quedaría relegado en territorio ibérico a un segundo plano ante la importancia de la imagen en sí misma (Moratalla y Verdú 2007: 359), de manera que en su éxito tendría mucho que ver su potencial como objeto de culto no específico, con múltiples lecturas y connotaciones, para adaptarse a las costumbres religiosas indígenas.

Estas figuras de arcilla constituyen una categoría muy particular de exvoto cuyo más claro representante es el "tipo Guardamar", al que pertenecen los dos fragmentos presentados (fig. 16), en el que no se aprecia rasgo alguno de su función originaria. Su ausencia en necrópolis (García 2015: 87 y 93) incide en este aprovechamiento exclusivo, mientras que los modelos de rasgos "canónicos" quizás se reservaran para los rituales funerarios. Esta distinción funcional explicaría, entre otros factores, tanto la variedad morfológica como la convivencia de tipos. A partir de los resultados ofrecidos en el reciente estudio sobre el conjunto de terracotas del santuario de la Serreta, todo parece indicar que, en términos generales, la figura del oferente es sustituida a partir del s. II a.C. por la imagen esquemática de la propia deidad a la que se rinde culto, cuyo elemento principal es el rostro (Amorós y Grau 2017: 167-168), de ahí el hallazgo reiterado de esta parte concreta en santuarios ibéricos. Se trata de la representación simbólica de la divinidad local, en torno a la cual se articulan las prácticas rituales en época tardía. Es más, los pebeteros "tipo Guardamar", versión contestana de los pebeteros clásicos, sirven como ejemplo de un proceso de simplificación de rasgos y elementos decorativos que puede rastrearse no sólo en el SE sino también en el S peninsular y otros territorios mediterráneos que habían permanecido bajo la órbita cartaginesa como Cerdeña o Ibiza (Grau et al. 2017: 86).

El empleo de estas piezas, independientemente de que también se efectuara un culto privado, informa sobre todo de unos ritos de tipo popular en los que debieron participar sectores cada vez más amplios de la sociedad (Grau 2010: 114-117) y que serían compartidos con otras comunidades de la región. De manera periódica, tras una corta peregrinación o romería, estos objetos de modesta artesanía eran depositados en espacios públicos cercanos a los asentamientos, como sucedería en la Serreta (Llobregat et al. 1992: 69), realizándose además comidas y/o libaciones, todo ello en torno a la devoción por una divinidad femenina protectora (Moneo 2003: 106). El santuario alcoyano se ha interpretado como un punto integrador del poblamiento de ibérico de esta unidad territorial (Grau 2000: 197 y 216-217; Amorós y Grau 2017: 182), desarrollándose en él una serie de relaciones sociales y

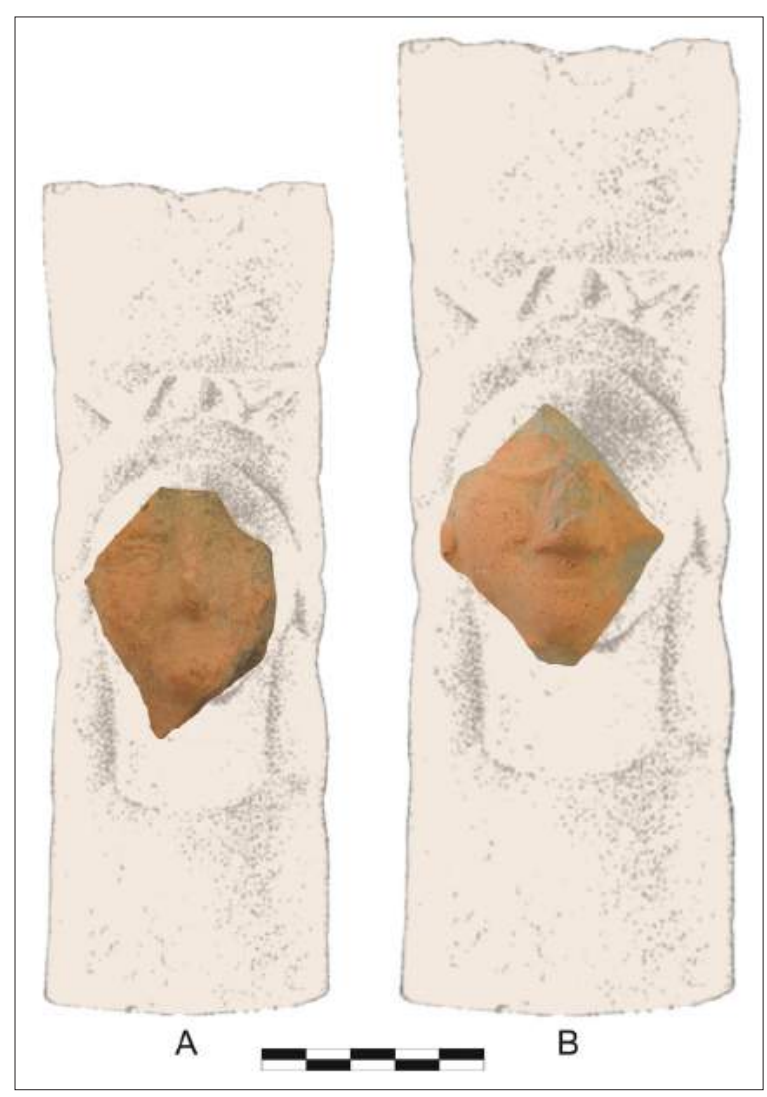

Fig. 16: Reconstrucción aproximada del aspecto de los pebeteros estudiados: A. Ejemplar de Aspe. B. Pebetero del Peñón de Ifach. 
económicas que servirían para reforzar la cohesión de las comunidades indígenas a escala comarcal y para reivindicar su territorio (García 2015: 90-92 y 95). Es más, tras el abandono del poblado, el santuario adjunto se convertiría en un espacio de culto de carácter rural, en conexión con otros núcleos cercanos. Continuaron efectuándose ofrendas, si bien las figurillas de oferentes masculinos y femeninos de arcilla, propias del s. III a.C., dieron paso a otro tipo de ítems, básicamente los pebeteros "tipo Guardamar" (Amorós y Grau 2017: 165-167).

Por otra parte, conviene resaltar el elevado nivel de fractura de hallazgos como los del Castillo de Guardamar, al igual que sucede con otros repertorios documentados en el ámbito semita, caso de Gadir (Niveau de Villedary y Córdoba 2003: 127 y 136), consecuencia del desarrollo del propio ritual. Este factor dificulta en buena medida el recuento definitivo de individuos, del mismo modo que la escasez, por no decir ausencia, de restos constructivos asociados complica la interpretación de estos conjuntos. La falta de contextos fiables supone también un importante obstáculo, sobre todo a la hora de determinar dataciones. Cabe destacar al respecto las bajas cronologías ofrecidas por los ejemplares meridionales, para los cuales, como ocurre en las áreas gaditana o malagueña, se ha retrasado su producción hasta el s. I a.C. (Niveau de Villedary 2007: 177; Mora y Arancibia 2014: 56; Niveau de Villedary y Martelo 2014: 164-167), hecho que no parece entrar en contradicción con la ya aludida datación tardía otorgada tradicionalmente al "tipo Guardamar", cuya producción debió iniciarse hacia mediados o finales del s. III a.C.

\section{CONCLUSIONES}

El fragmento de pebetero de Ifach contribuye a caracterizar un establecimiento ibérico del que aún disponemos de poca información, pero cuya posición preeminente en altura y en un ambiente costero sugiere un decidido interés por el control de los recursos económicos y simbólico del territorio. Cumple además con los preceptos esenciales de un auténtico centro rector (con la salvedad quizás de su tamaño), al situarse en un punto estratégico, con un amplio dominio visual y un marcado aislamiento debido a las características topográficas del lugar, con acusadas pendientes y relieves escarpados conformando defensas naturales (Grau 2004: 64-65 y 189). El desarrollo de este asentamiento, que acontece durante el Ibérico Pleno, se inserta en un proceso de crecimiento y consolidación de los núcleos preexistentes y encaja en un modelo de poblamiento jerarquizado (Costa y Castelló 1999; Grau 2002: 131).

La singular localización en el litoral alicantino del yacimiento de Calp redunda en la ubicación preferente de centros de culto suprarregional como podría ser el situado en el Castillo de Guardamar o el de La Algaida (Sanlúcar de Barrameda, Cádiz), éste último sobre una península que se adentra en las marismas de la desembocadura del Guadalquivir (Marín 2010: 219 ss.). En este lugar se debió efectuar un culto en área abierta, depositándose ofrendas cerámicas y exvotos de terracota, entre ellos pebeteros (Ferrer 2002: 198-202; Corzo 2007: 206 ss., fig. 6).

Del ejemplar calpino se desprende el cariz "punicizante" que caracteriza a la Contestania ibérica, reflejo de la impronta ejercida sobre las comunidades indígenas primero por el comercio semita y más tarde por la llegada de tropas cartaginesas ${ }^{12}$, pero sobre todo de la provechosas relaciones establecidas entre ambos grupos, cuyo resultado sería la proliferación de objetos y el reconocimiento de prácticas compartidas e identidades híbridas (Aranegui y Vives-Ferrándiz 2017: 27). En este sentido, los estudios en curso están revelando una considerable presencia de ánforas púnicas de origen ebusitano y del denominado "círculo del Estrecho", así como de morteros y cerámicas de imitación también púnico-ebusitanas, en consonancia con otros repertorios contestanos conocidos. Lejos de servir para determinar la existencia de una población extranjera, el hallazgo del fragmento de pebetero, como ocurriría en el caso de Aspe, resulta de gran interés para perfilar un contexto simbólico-religioso muy particular, determinado por el carácter permeable de estas sociedades indígenas. La imagen simplificada de la divinidad entronca con la tradición ibérica e informa a su vez de los cambios que se producen en estas comunidades con la conquista romana, erigiéndose como un elemento cohesionador por lo reiterado de su aparición en estas tierras.

Desgraciadamente, ignoramos el contexto exacto al que pertenecería la pieza más allá de la posición estratigráfica en que se halló. La UE 1154 corresponde a la fase de ocupación medieval cristiana de la pobla de Ifach, identificándose en ella una selección de cerámicas protohistóricas completamente descontextualizadas, entre ellas apenas una docena de formas reconocibles (un fragmento de asa de barniz negro ático y varios de ánforas, cerámicas pintadas y comunes ibéricas), que convendría interpretar como consecuencia del acarreo y depósito de tierras para el relleno de las estructuras posteriores. 
Que el pebetero pudiera proceder de algún tipo de recinto sacro dentro del poblado es una hipótesis que nos parece perfectamente viable, pero que a luz de los restos conservados resulta, por el momento, difícil de confirmar.

En cuanto al poblado ibérico de Castillo del Río, pese a la destrucción provocada por los niveles almohades, es muy posible que ejerciera como centro gestor del territorio del Medio Vinalopó. En este entorno ostentaría también una relevante posición Tres Hermanas, en donde se localizó una construcción de planta casi cuadrada, de $9 \mathrm{~m}$ de lado, con una antesala alargada y cella tripartita, interpretada como la residencia de una autoridad local o regia, o quizás un santuario rural (Moratalla 2015: 117-119; Rouillard et al. 2015: 103). En el transcurso de las últimas campañas de excavación no se han localizado evidencias de fortificación alguna, aunque sí varias casas independientes dispersas por el área, que albergarían a una comunidad no muy numerosa.

Aspe se encuentra a medio camino entre los dos grandes núcleos ibéricos en el Vinalopó: El Monastil (Elda) en su parte media-alta y sobre todo l'Alcúdia, en la baja (Moratalla 2005: 110 ss.; 2015: 114 y 119, fig. 1). De este modo, el poblado existente en Castillo del Río, próximo a tierras de cultivo y a importantes vías de comunicación, se aseguraría el control del territorio, cumpliendo así con una serie de condicionantes que también se identifican en otros emplazamientos de tipo sacro con presencia de pebeteros, caso del santuario de Coimbra del Barranco Ancho, que domina el valle de El Prado y se vincula a un importante oppidum (García et al. 1991-92; 1997: 239, fig. 1). Estos centros de culto comunitario se definen por su localización estratégica sobre cumbres o laderas de colinas o montañas destacadas, desde las que las que se visualizan claramente regiones o comarcas en las que se efectúa una intensa explotación de tipo agrícola, ganadera o de otros recursos tan preciados como la sal, cuya producción y comercialización pudo desarrollarse en el entorno de Ifach (Bolufer y Sala 2009: 66-67).

\section{NOTAS}

1. Agradecemos todas las facilidades ofrecidas por su directora, María Berná García, la cual nos permitió no sólo tener acceso a la pieza sino que también nos proporcionó información sobre su origen, así como al propio donante, cuyas indicaciones reproducimos.

2. A los que habría que añadir el descubrimiento casual de ocho monedas hispánicas del s. II a.C., recogidas por aficionados (García 2008: 93-94).
3. Tras las primeras excavaciones desarrolladas en 1928 por Martínez y Martínez, el cual contó con la colaboración de Adolf Schulten y Otto Jessen, cabe citar los trabajos dirigidos por José Belda entre los años 1963 y 1964, así como las exploraciones efectuadas en los años 60 por el norteamericano W. L. Dwyer y las campañas de Carmen Aranegui entre los años 1975 y 1977. Estas últimas permitieron confirmar una ocupación del lugar desde la Edad del Bronce hasta época bajoimperial, constatándose estructuras ibéricas muy deterioradas, con una cronología de la segunda mitad del s. V al I a.C. (Aranegui 1986: 53).

4. En esta ocasión debemos agradecer a José Luis Menéndez Fueyo, director del proyecto de investigación de la pobla medieval de Ifach, el haber autorizado nuestra petición para estudiar y publicar esta pieza.

5. Atendiendo a las dimensiones medias de los pebeteros completos, el ejemplar de Ifach podría alcanzar los $20 \mathrm{~cm}$ de altura y unos $7 \mathrm{~cm}$ de diámetro, siendo el de Aspe algo más pequeño.

6. Conviene, sin embargo, ser cautos en cuanto a esta atribución puesto que existen serias dudas sobre la procedencia exacta de tales piezas, pudiendo pertenecer algunas a las excavaciones de Belda en Benidorm.

7. Horn (2011) corrobora la cronología del s. III a inicios del II a.C. a partir de la comparación estilística con los ejemplares del santuario de la Serreta (Alcoi).

8. Que podríamos definir como el modelo más representativo, de tendencia cilíndrica pero con sus distintos componentes bien diferenciados (cuello, cabeza, tocado) y los atributos habituales (hojas y frutos en el cabello, aves sobre la frente, pendientes de racimo y broche circular), todo ello plasmado de manera idealizada y armónica, guardando las proporciones y de una cierta calidad general (Moratalla y Verdú 2007: 350 ss.).

9. Caso de los ejemplares púnico-ebusitanos conservados en el Museu d'Arqueologia de Barcelona o del Museu Arqueològic d'Eivissa (Vives 1917: láms. LXXI-LXXII; García y Bellido 1948: 198, lám. CXLVII; Tarradell 1974: 150-151; Almagro 1980a: 215, 216 y 221, láms. CXLV y CLIII; 1980b: 95-96, láms. LVII y LVIX; San Nicolás 1987: lám XIII, nº 7, entre otras referencias) o el procedente de la necrópolis de l'Albufereta (Lafuente 1934: 28, lám. X; Nordström 1961: 75, lám. XXXVI; Rubio 1986: 216, fig. 97; Verdú 2015: 240, fig. 3.226).

10. Sirvan de ejemplo para el yacimiento del Campello el lote de fragmentos CS 14961, mientras que entre el conjunto del Tossal de la Cala destaca el pebetero incompleto CS 15291. En ambos casos se trata de hallazgos antiguos efectuados en los años 30 y 40 del s. XX respectivamente.

11. Un ejemplo reciente de análisis de pastas aplicados a pebeteros es el de C. P. Odriozola (2014).

12. En cuanto al tema de la interacción entre las poblaciones ibéricas del SE peninsular y el factor púnico cabe citar los recientes estudios de C. Aranegui y J. Vives-Ferrándiz (2014; 2017).

\section{BIBLIOGRAFÍA}

ABAD, L. (1986): Castillo de Guardamar, Arqueología en Alicante, 1976-86, Instituto de Cultura "Juan Gil-Albert", Alicante, 151-152.

ABAD, L. (1987): El poblamiento ibérico en la provincia de Alicante, Iberos. Actas de las I Jornadas sobre el Mundo Ibérico (Jaén, 1985) (A. Ruíz, M. Molinos, eds.), Jaén, 157-169. 
ABAD, L. (1992): Terracotas ibéricas del Castillo de Guardamar, Estudios de Arqueología Ibérica y Romana. Hom. a E. Pla Ballester, Serie de Trabajos Varios. S.I.P. 89, València, 225-237.

ABAD, L. (2010): Terracotas ibéricas del Castillo de Guardamar, Guardamar del Segura. Arqueología y Museo, Museo Arqueológico de Alicante-MARQ, 122-133.

ABAD, L.; SALA, F. (1997): Sobre el posible uso cúltico de algunos edificios de la Contestania ibérica, Espacios y lugares cultuales en el mundo ibérico, CPAC 18, 91-102.

ABAD, L.; SALA, F.; MORATALLA, J. (2017): El Bajo Segura hasta la II Guerra Púnica. Nuevas investigaciones, El Oriente de Occidente. Fenicios y púnicos en el área ibérica. VIII ${ }^{\circ}$ Coloquio Internacional del CEFYP (F. Prados, F. Sala, eds.), Alicante, 233-256.

ALMAGRO, M. J. (1980a): Corpus de las terracotas de Ibiza, Bibliotheca Praehistorica Hispana XVIII, Madrid.

ALMAGRO, M. J. (1980b): Catálogo de las terracotas de Ibiza en el Museo Arqueológico Nacional, Madrid.

ALMAGRO, M. J. (1983): Un depósito votivo de terracotas en Villaricos, Hom. al Profesor M. Almagro Basch II, 291-308.

AMORÓS, I.; GRAU, I. (2017): El santuario en tiempos de la implantación romana, El santuario ibérico y romano de $\mathrm{La}$ Serreta (Alcoi, Cocentaina, Penàguila). Prácticas rituales y paisaje en el área central de la Contestania (I. Grau, I. Amorós, J. M. Segura, eds.), Alcoi, 161-182.

ARANEGUI, C. (1986): Peñón de Ifach, Arqueología en Alicante, 1976-1986, Instituto de Cultura “Juan Gil-Albert”, Alicante, 53-54.

ARANEGUI, C. (1994): Iberia sacra loca. Entre el Cabo de la Nao, Cartagena y El Cerro de los Santos, Revista de Estudios Ibéricos 1, 115-138.

ARANEGUI, C. (2015): Arqueología e Historia del sucronensis sinus en época ibérica, $E l$ sucronensis sinus en época ibérica (C. Aranegui, ed.), Saguntum Extra 17, València, 9-25.

ARANEGUI, C.; VIVES-FERRÁNDIZ, J. (2014): More than neighbours: Punic-Iberian connections in southeast Iberia, The Punic Mediterranean. Identities and Identification from Phoenician Settlement to Roman Rule (J. Crawley, N. C. Vella, eds.), Cambridge, 243-256.

ARANEGUI, C.; VIVES-FERRÁNDIZ, J. (2017): Desmontando paradigmas. Fenicios y púnicos en el Oriente de Occidente, El Oriente de Occidente. Fenicios y púnicos en el área ibérica. VIII ${ }^{\circ}$ Coloquio Internacional del CEFYP (F. Prados, F. Sala, eds.), Alicante, 25-50.

AZUAR, R. (1986): Castillo del Río, Arqueología en Alicante, 1976-1986, Instituto de Cultura "Juan Gil-Albert", Alicante, $112-114$.

AZUAR, R. (1994): El Castillo del Río (Aspe, Alicante). Arqueología de un asentamiento andalusí y la transición al feudalismo (siglos XII-XIII), Alicante.

BAYO, S. (2010): El yacimiento ibérico de "El Tossal de la Cala". Nuevo estudio de los materiales depositados en el MARQ correspondientes a las excavaciones de José Belda y Miquel Tarradell, Museo Arqueológico de Alicante-MARQ, Trabajos de Arqueología 1, Alicante.

BELDA, J. (1947): Algunos restos del antiguo culto a la diosa religioso funeraria, II Congreso Arqueológico del sudeste Español (Albacete, 1946), 236-259.

BOLUFER, J.; SALA, F. (2009): Una torre de guaita ibera al Tossal de l'Empedrola (Calp, Marina Alta), Calp. Arqueología y Museo, Museo Arqueológico de Alicante-MARQ, 54-67.

CORZO, R. (2007): La coroplastia en el santuario de La Algaida (Sanlúcar de Barrameda, Cádiz), Imagen y culto en la Iberia prerromana: los pebeteros en forma de cabeza femenina (M. C. Marín, F. Horn, eds.), Spal Monografías IX, 195-217.

COSTA, P.; CASTELLÓ, J. S. (1999): La Cultura Ibérica: poblamiento y hábitat, Historia de La Marina Alta, Alicante, 97-108.

COSTA, B.; JIMÉNEZ, H.; LÓPEZ, J. M. (2017): La adopción de modelos foráneos en la Ibiza púnica: dos moldes para la elaboración de terracotas hallados en la isla, Boletín del Museo Arqueológico Nacional 36, 191-210.

FERRER, E. (2002): Topografía sagrada del Extremo Occidente: santuarios, templos y lugares de culto en la Iberia púnica, Ex Oriente Lux: las religiones orientales antiguas en la Península Ibérica (E. Ferrer, ed.), Spal Monografías II, 185-217.

FERRER, E.; PRADOS, E. (2007): Los pebeteros en forma de cabeza femenina en el contexto de las comunidades púnicas de Iberia, Imagen y culto en la Iberia prerromana: los pebeteros en forma de cabeza femenina (M.C. Marín, F. Horn, eds.), Spal Monografías IX, 121-138.

GALLELLO, G.; GRAU, I. (2017): Lo que no se ve en la arcilla: análisis del componente mineral por XRF de las terracotas del santuario, El santuario ibérico y romano de La Serreta (Alcoi, Cocentaina, Penàguila). Prácticas rituales y paisaje en el área central de la Contestania (I. Grau, I. Amorós, J. M. Segura, eds.), Alcoi, 119-126.

GARCÍA Y BELLIDO, A. (1948): Hispania graeca II, Barcelona.

GARCÍA, J. M.; INIESTA, Á.; PAGE, V. (1991-92): El santuario ibérico de Coimbra del Barranco Ancho (Jumilla, Murcia), Anales de Prehistoria y Arqueología de la Universidad de Murcia 7-8, 75-82.

GARCÍA, J. M.; HERNÁNDEZ, E.; INIESTA, Á.; PAGE, V. (1997): El santuario de Coimbra del Barranco Ancho (Jumilla, Murcia) a la luz de los nuevos hallazgos, Espacios y lugares cultuales en el mundo ibérico. CPAC 18, 239-255.

GARCÍA, J. M.; PAGE, V. (2004): Terracotas y vasos plásticos de la necrópolis del Cabecico del Tesoro, Verdolay, Murcia, Monografías del Museo de Arte Ibérico de El Cigarralejo 1, Murcia.

GARCÍA, J. (2015): Pebeteros en la costa. Santuarios, peregrinaciones y rituales en la Contestania ibérica (ss. III-II a. C.), Zephyrus LXXVI, 77-98.

GARCÍA, J. R. (2008): Arqueología en Aspe: poblamiento y territorio, Aspe. 
GARCÍA, J. R.; MORATALLA, J. (1998-99): Nuevos datos sobre arquitectura de prestigio ibérica. La regia de "Las Tres Hermanas" (Aspe, Alicante), Lucentum XVII-XVIII, 163182.

GARCÍA, A. (1992-93): El Castillo de Guardamar. Nuevos datos sobre el poblamiento ibérico en la desembocadura del río Segura, Alebus 2-3, 67-96.

GRAU, I. (2000): Territorio y lugares de culto en el área central de la Contestania ibérica, CPAC 21, 195-225.

GRAU, I. (2002): La organización del territorio en el área central de la Contestania Ibérica, Alicante.

GRAU, I. (2004): La construcción del paisaje ibérico. Aproximación al territorio protohistórico de la Marina Alta, Sagvntvm-PLAV 36: 61-75.

GRAU, I. (2010): Paisajes sagrados del área central de la Contestania ibérica, Debate en torno a la religiosidad protohistórica (T. Tortosa, S. Celestino, eds.), Anejos de AEA LV, Madrid, 101-122.

GRAU, I.; AMORÓS, I.; LÓPEZ-BELTRÁN, M. (2017): La colección de terracotas, El santuario ibérico y romano de La Serreta (Alcoi, Cocentaina, Penàguila). Prácticas rituales y paisaje en el área central de la Contestania (I. Grau, I. Amorós, J. M. Segura, eds.), Alcoi, 61-118.

GRAU, I.; GALLELLO, G. (2017): Assessing the territorial influence of an Iberian worship site. The chemical characterisation of the terracotta from the Iron Age sanctuary of La Serreta, Journal of Archaeological Science. Reports 13: 142-150.

DOI: https://doi.org/10.1016/j.jasrep.2017.03.045

GONZÁLEZ, A. (1975): El yacimiento ibérico del Castillo del Río. Aspe (Alicante), XIII Congreso Nacional de Arqueología (Zaragoza, 1975), 697-700.

GUSI, F. (1997): Lugares sagrados, divinidades, cultos y rituales en el levante de Iberia, Espacios y lugares cultuales en el mundo ibérico. CPAC 18, 171-209.

HORN, F. (2007): Les "brûle-parfums à figure féminine" en terre cuite de Baria (Villaricos, Almeria). Caractéristiques de production d'un atelier punique d'Andalousie occidentale, Imagen y culto en la Iberia prerromana: los pebeteros en forma de cabeza femenina (M. C. Marín, F. Horn, eds.), Spal Monografías IX, 257-283.

HORN, F. (2011): Ibères, grecs et puniques en Extrême-Occident. Les terres cuites de l'espace ibérique du VIIIe au IIe siècle av. J.-C., Bibliothèque de la Casa de Velázquez 54, Madrid.

HORN, F.; MORATALLA, J. (2014): Les terres cuites, Villajoyosa Antique (Alicante, Espagne). Territoire et topographie. Le sanctuaire de La Malladeta (P. Rouillard, A. Espinosa, J. Moratalla, eds.), Collection de la Casa de Velázquez 141, Madrid, 156-171.

JUAN, J. (1987-88): El conjunt de terracotes votives del santuari ibèric de la Serreta (Alcoi, Cocentaina, Penàguila), Sagvntvm-PLAV 21, 295-329.
JUAN, J. (1990): La plástica ibérica en arcilla de la provincia de Alicante, Ayudas a la investigación del Instituto de Cultura “Juan Gil-Albert” 1986-87 III. Arqueología, Arte, Toponimia, Alicante, 139-145.

LAFUENTE, J. (1934): Excavaciones en la Albufereta de Alicante (antigua Lucentum), Junta Superior del Tesoro Artístico, Sección de Excavaciones 126, Madrid.

LÓPEZ, J. L. (2001-02): Un santuario rural en Baria, II Congreso Internacional del Mundo Púnico (Cartagena, 2000). Estudios Orientales 5-6, 77-89.

LÓPEZ, J. M.; MARLASCA, R.; ESCANDELL, M. J. (2014): El yacimiento de es Rafal (Puig d'en Valls, Eivissa) y dos pebeteros en forma de cabeza femenina, Imagen y culto en la Iberia prerromana II: Nuevas lecturas sobre los pebeteros en forma de cabeza femenina (M.C. Marín, A. M. Jiménez, coords.), Spal Monografías XVIII, 61-83.

LÓPEZ, E. (1997): El alfar ibérico, La Illeta dels Banyets (El Campello, Alicante). Estudios de la Edad del Bronce y Época Ibérica (M. H. Olcina, ed.), Museo Arqueológico de Alicante-MARQ, Serie Mayor 1, Alicante, 221-250.

LÓPEZ-BERTRAN, M. (2015): Paisajes rituales en el sucronensis sinus, El sucronensis sinus en época ibérica (C. Aranegui, ed.), Saguntum Extra 17, 43-62.

LLOBREGAT, E. A. (1972): Contestania Ibérica, Instituto de Estudios Alicantinos, serie II, ${ }^{\circ} 2$, Alicante.

LLOBREGAT, E. A. (1988): Un conjunto de templos ibéricos del s. IV a. C. hallado en las excavaciones de la isla de el Campello (Alicante), Hom. a Samuel de los Santos, Instituto de Estudios Albacetenses, Albacete, 137-143.

LLOBREGAT, E. A.; CORTELL, E.; JUAN, J.; SEGURA, J. M. (1992): El urbanismo ibérico en La Serreta”, Recerques del Museu d'Alcoi 1, 37-70.

MARÍN, M. C. (1987): ¿Tanit en España?, Lucentum 6, 43-79.

MARÍN, M. C. (2001-02): Observaciones en torno a los pebeteros en forma de cabeza femenina, II Congreso Internacional del Mundo Púnico (Cartagena, 2000). Estudios Orientales 5-6, 319-335.

MARÍN, M. C. (2010): Santuarios prerromanos de la costa atlántica andaluza, Debate en torno a la religiosidad protohistórica (T. Tortosa, S. Celestino, eds.), Anejos de AEA LV, Madrid, 219-243.

MONEO, T. (2003): Religio iberica. Santuarios, ritos y divinidades (siglos VII-I a. C.), Bibliotheca Archaeologica Hispana 20, Madrid.

MORATALLA, J. (2004): Organización del territorio y modelos de poblamiento en la Contestania ibérica, Tesis doctoral inédita, Universidad de Alicante.

MORATALLA, J. (2005): El territorio meridional de la Contestania, La Contestania ibérica, treinta años después. Actas de las I Jornadas de Arqueología Ibérica del Área de Arqueología de la Universidad de Alicante (24-26 de octubre de 2002) (L. Abad, F. Sala, I. Grau, eds.), Publicaciones de la Universidad de Alicante, Serie Arqueología, 91-117. 
MORATALLA, J. (2015): Aspe en el territorio ibérico contestano: luces y sombras de un proceso histórico, Aspe a la luz de la Arqueología (M. T. Berná, F. F. Tordera, coords.), Aspe, 113-119.

MORATALLA, J.; VERDÚ, E. (2007): Pebeteros con forma de cabeza femenina de la Contestania ibérica, Imagen y culto en la Iberia prerromana: los pebeteros en forma de cabeza femenina (M. C. Marín, F. Horn, eds.), Spal Monografías IX, 339-366.

MORA, B.; ARANCIBIA, A. (2014): Pebeteros en forma de cabeza femenina procedentes de los territorios malacitanos, Imagen y culto en la Iberia prerromana II: Nuevas lecturas sobre los pebeteros en forma de cabeza femenina (M. C. Marín, A. M. Jiménez, coords.), Spal Monografías XVIII, 35-59.

MUÑOZ, A. M. (1963): Pebeteros ibéricos en forma de cabeza femenina (De coroplastia ibérica I), Instituto de Arqueología de la Universidad de Barcelona, Publicaciones Eventuales 5, Barcelona.

NIVEAU DE VILLEDARY, A. M. (2007): Nuevos datos sobre la presencia de "pebeteros en forma de cabeza femenina" en la bahía de Cádiz, Imagen y culto en la Iberia prerromana: los pebeteros en forma de cabeza femenina (M. C. Marín, F. Horn, eds.), Spal Monografías, IX, 151-194.

NIVEAU DE VILLEDARY, A. M. (2017): Nuevos datos sobre la evolución formal y estilística de los "pebeteros en forma de cabeza femenina”. A propósito del ejemplar de Torralba d'en Salord (Alaior, Menorca), Menorca entre fenicios y púnicos (F. Prados, H. Jiménez, J. J. Martínez, coords.), Monografías del Centro de Estudios del Próximo Oriente y la Antigüedad Tardía 2, Publicacions des Born 25, 85-103.

NIVEAU DE VILLEDARY, A. M.; BLANCO, F. J. (2007): Continuidad púnica en la Gades republicana. La producción vascular del horno de la Calle Troilo, Spal 16, 195-224.

NIVEAU DE VILLEDARY, A.M.; CÓRDOBA, I. (2003): Algunas consideraciones sobre la religiosidad de Gadir. Nuevos datos para su estudio, Sagvntvm-PLAV 35, 123-145.

NIVEAU DE VILLEDARY, A. M.; MARTELO, M. A. (2014): Puntualizaciones sobre los "pebeteros en forma de cabeza femenina" tardopúnicos. A propósito de un hallazgo reciente, Imagen y culto en la Iberia prerromana II: Nuevas lecturas sobre los pebeteros en forma de cabeza femenina (M. C. Marín, A. M. Jiménez, coords.), Spal Monografías XVIII, 155-171.

NORDSTRÖM, S. (1961): Los cartagineses en la costa alicantina, Alicante.

ODRIOZOLA, C. P. (2014): Estudio arqueométrico de algunos pebeteros con forma de cabeza femenina del Mediterráneo occidental, Imagen y culto en la Iberia prerromana II: Nuevas lecturas sobre los pebeteros en forma de cabeza femenina (M. C. Marín, A. M. Jiménez, coords.), Spal Monografías XVIII, 215-228.
OLCINA, M. H. (2010): La época romana, Guardamar del Segura. Arqueología y Museo, Museo Arqueológico de AlicanteMARQ, 134-153.

OLCINA, M. H.; LÓPEZ, E. (1997): Prospección y excavación de urgencia en los alrededores del alfar ibérico, La Illeta dels Banyets (El Campello, Alicante). Estudios de la Edad del Bronce y Época Ibérica (M. H. Olcina, ed.), Museo Arqueológico de Alicante-MARQ, Serie Mayor 1, Alicante, 207-220.

OLCINA, M. H.; MARTÍNEZ, A.; SALA, F. (2009): La Illeta dels Banyets (El Campello, Alicante). Épocas Ibérica y Romana I. Historia de la investigación y sintesis de las intervenciones recientes (2000-2003), Museo Arqueológico de Alicante-MARQ, Serie Mayor 7, Alicante.

PENA, M. J. (1987): Los thymiateria en forma de cabeza femenina hallados en el N.-E. de la Península Ibérica, Grecs et ibères au IVe siècle avant Jesus Christ. Commerce et iconographie, REA 89, 349-358.

PENA, M. J. (2007): Reflexiones sobre los pebeteros en forma de cabeza femenina, Imagen y culto en la Iberia prerromana: los pebeteros en forma de cabeza femenina (M. C. Marín, F. Horn, eds.), Spal Monografías IX, 17-40.

PERDIGUERO, P. (2016): Los espacios de producción costeros en la esfera de influencia púnica: el caso de la Illeta dels Banyets (El Campello, Alicante), Trabajo de fin de Máster en Arqueología Profesional y Gestión del Patrimonio, Alicante.

PERDIGUERO, P. (2017): Reflexión en torno al binomio religiónproducción en el Mediterráneo occidental (siglos VI-III A.C.), Convergencia y transversalidad en humanidades. Actas de las VII Jornadas de investigación de la Facultad de Filosofía y Letras de la Universidad de Alicante (6-7 de abril de 2017) (E. Cutillas, coord.), 211-217.

RAMON, J. (2011): El sector alfarero de la ciudad púnica de Ibiza, YOSERIM. La producción alfarera fenicio-púnica en Occidente. XXI Jornadas de Arqueología Fenicio-Púnica (Eivissa, 2010) (B. Costa, J. H. Fernández, eds.), Treballs del Museu Arqueològic d'Eivissa i Formentera 66, 165-222.

ROSSER, P.; FUENTES, C. (2007): El yacimiento arqueológico del Tossal de les Basses. Seis mil años de historia de Alicante, Alicante.

ROUILLARD, P.; MORATALLA, J.; BERNÁ, M. T. (2015): Tres Hermanas-2014: Prospección y primera campaña de excavación, Aspe a la luz de la Arqueología (M. T. Berná, F. F. Tordera, coords.), Aspe, 98-103.

RUBIO, F. (1986): La necrópolis ibérica de La Albufereta de Alicante (Valencia, España), Academia de Cultura Valenciana, Serie Arqueológica 11, Valencia.

SALA, F.; VERDÚ, E. (2014): Pebeteros en forma de cabeza femenina en la Contestania. Estado de la cuestión y perspectivas de estudio, Imagen y culto en la Iberia prerromana II: Nuevas lecturas sobre los pebeteros en forma de cabeza femenina (M. C. Marín, A. M. Jiménez, coords.), Spal Monografías XVIII, 19-34. 


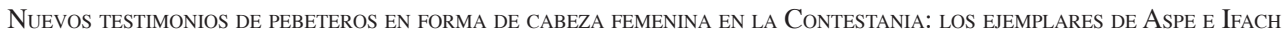

SAN NICOLÁS, M. P. (1987): Las terracotas figuradas de la Ibiza púnica, Consiglio Nazionale delle Ricerche, Istituto per la Civiltà Fenicia e Punica, Collezione di Studi Fenici 25, Roma.

TARRADELL, M. (1974): Terracotas púnicas de Ibiza, Barcelona. VERDÚ, E. (2005): Francisco Figueras Pacheco y las excavaciones en la necrópolis de La Albufereta de Alicante (19341936), Museo Arqueológico de Alicante-MARQ, Serie Mayor 4, Alicante.
VERDÚ, E. (2009): El jinete y el monstruo. Un oinokhóe ibérico decorado de Ifach, Calp. Arqueología y Museo, Museo Arqueológico de Alicante-MARQ, 68-83.

VERDÚ, E. (2015): La necrópolis ibérica de l'Albufereta (Alacant). Ritos y usos funerarios en un contexto de interacción cultural, Museo Arqueológico de Alicante-MARQ, Serie Mayor 11, Alicante.

VIVES, A. (1917): Estudio de arqueología cartaginesa. La necrópoli de Ibiza, Madrid. 